\title{
Wind speed response of marine non-precipitating stratocumulus clouds over a diurnal cycle in cloud-system resolving simulations
}

\author{
Jan Kazil $^{1,2}$, Graham Feingold ${ }^{2}$, and Takanobu Yamaguchi ${ }^{1,2}$ \\ ${ }^{1}$ Cooperative Institute for Research in Environmental Sciences (CIRES), University of Colorado, Boulder, Colorado, USA \\ ${ }^{2}$ Chemical Sciences Division, Earth System Research Laboratory, NOAA, Boulder, Colorado, USA \\ Correspondence to: Jan Kazil (jan.kazil@noaa.gov)
}

Received: 2 September 2015 - Published in Atmos. Chem. Phys. Discuss.: 21 October 2015

Revised: 28 January 2016 - Accepted: 24 March 2016 - Published: 12 May 2016

\begin{abstract}
Observed and projected trends in large-scale wind speed over the oceans prompt the question: how do marine stratocumulus clouds and their radiative properties respond to changes in large-scale wind speed? Wind speed drives the surface fluxes of sensible heat, moisture, and momentum and thereby acts on cloud liquid water path (LWP) and cloud radiative properties. We present an investigation of the dynamical response of non-precipitating, overcast marine stratocumulus clouds to different wind speeds over the course of a diurnal cycle, all else equal. In cloud-system resolving simulations, we find that higher wind speed leads to faster boundary layer growth and stronger entrainment. The dynamical driver is enhanced buoyant production of turbulence kinetic energy (TKE) from latent heat release in cloud updrafts. LWP is enhanced during the night and in the morning at higher wind speed, and more strongly suppressed later in the day. Wind speed hence accentuates the diurnal LWP cycle by expanding the morning-afternoon contrast. The higher LWP at higher wind speed does not, however, enhance cloud top cooling because in clouds with LWP $\gtrsim 50 \mathrm{~g} \mathrm{~m}^{-2}$, longwave emissions are insensitive to LWP. This leads to the general conclusion that in sufficiently thick stratocumulus clouds, additional boundary layer growth and entrainment due to a boundary layer moistening arises by stronger production of TKE from latent heat release in cloud updrafts, rather than from enhanced longwave cooling. We find that large-scale wind modulates boundary layer decoupling. At nighttime and at low wind speed during daytime, it enhances decoupling in part by faster boundary layer growth and stronger entrainment and in part because shear from large-scale wind in the sub-cloud layer hinders vertical moisture transport between the surface and cloud base. With increasing wind speed, how-
\end{abstract}

ever, in decoupled daytime conditions, shear-driven circulation due to large-scale wind takes over from buoyancy-driven circulation in transporting moisture from the surface to cloud base and thereby reduces decoupling and helps maintain LWP. The total (shortwave + longwave) cloud radiative effect (CRE) responds to changes in LWP and cloud fraction, and higher wind speed translates to a stronger diurnally averaged total CRE. However, the sensitivity of the diurnally averaged total CRE to wind speed decreases with increasing wind speed.

\section{Introduction}

Clouds are a linchpin in Earth's climate system because of their impact on Earth's radiation budget (Hartmann and Doelling, 1991). Low clouds, and in particular marine boundary layer (BL) clouds, exert stronger leverage over reflected solar radiation compared to other cloud types (Hartmann and Short, 1980; Hartmann et al., 1992). With their response to environmental conditions, clouds amplify (positive cloud feedback) or dampen (negative cloud feedback) the effects of climate forcing or internal climate variability (Schneider, 1972; Stephens, 2005). Cloud feedbacks are a major source of uncertainty in climate simulations (Webb et al., 2006; Williams and Tselioudis, 2007; Wyant et al., 2006). The uncertainty related to low clouds originates primarily from marine stratocumulus and trade wind cumulus clouds (Bony and Dufresne, 2005; Soden and Vecchi, 2011). Recent observational and model studies have identified a positive low-level cloud feedback (Clement et al., 2009; Brient and Bony, 2013; Bretherton et al., 2014; Dal Gesso et al., 
2015), although a strong negative low cloud feedback in response to short-term climate variations has been found as well (Zhou et al., 2013). The sign, magnitude, and mechanisms of the response and feedback of low clouds to climate change are far from understood and the subject has garnered scrutiny with models that resolve processes in more detail than climate models.

Caldwell and Bretherton (2009) found, using a mixed layer model, that a warmer climate would be accompanied by a negative cloud feedback from stratocumulus clouds, caused by a cloud thickening due to weaker mean subsidence and a stronger inversion. Xu et al. (2010) used a large eddy simulation (LES) model to investigate the response of shallow cumulus and overcast stratocumulus clouds in an idealized climate change scenario, represented by a $2 \mathrm{~K}$ warmer sea surface temperature (SST). They identified a negative cloud feedback arising from the increase of cloud geometric thickness, liquid water path (LWP), cloud optical thickness, and inversion height with SST. Blossey et al. (2013) investigated marine low cloud sensitivity to idealized climate change ( $2 \mathrm{~K}$ SST warming) in a LES intercomparison study. The study covered the well-mixed stratocumulus, decoupled stratocumulus, and shallow cumulus cloud regimes. Most of the models in the intercomparison produced a negative cloud feedback for the well-mixed stratocumulus cloud regime, and a neutral or positive cloud feedback for the decoupled stratocumulus and the shallow cumulus cloud regime. Bretherton et al. (2013) expanded the investigation by considering changes in temperature, free-tropospheric relative humidity, carbon dioxide $\left(\mathrm{CO}_{2}\right)$ concentration, subsidence strength, inversion stability, and wind speed. The setup of their study allowed an estimate of the cloud response to a World Climate Research Program Coupled Model Intercomparison Project (CMIP3, Meehl et al., 2007) multimodel mean forcing for a particular greenhouse gas emission scenario. For a CMIP3 $2 \times \mathrm{CO}_{2}$ forcing, a positive shortwave cloud feedback resulted for the well-mixed stratocumulus, decoupled stratocumulus, and shallow cumulus cloud regime. Bretherton et al. (2013) concluded that this result, relative to that of Caldwell and Bretherton (2009) and Xu et al. (2010), arose from accounting for the radiative effect of the additional $\mathrm{CO}_{2}$ in their simulations, and from different assumptions on subsidence in a warmer climate and on the advection of heat and moisture. van der Dussen et al. (2015) systematically investigated the effect of a $2 \mathrm{~K}$ warming at constant relative humidity on a stratocumulus clouds for a range of free-tropospheric thermodynamic conditions. They found that the stratocumulus cloud responded under all considered free-tropospheric conditions with a LWP reduction and hence with a positive cloud feedback.

Combined, the current understanding indicates a positive globally integrated low cloud feedback in the climate system which is a composite of local responses that depend on cloud state and environmental conditions. Understanding of the various mechanisms by which the cloud states respond to changes in environmental conditions that accompany climate change is needed to build a dependable foundation for the representation of low-level clouds in climate simulations.

An understudied cloud-climate feedback mechanism is the response of BL clouds to changes in large-scale wind speed. Colón-Robles et al. (2006) observed that weak surface winds were associated with fewer activated cloud droplets in trade wind cumulus clouds, and they concluded that higher cloud droplet concentrations are more likely under conditions of stronger low-level wind speeds, primarily because stronger low-level wind speeds are associated with more intense cloud base updrafts. Chen et al. (2011) investigated aerosol-cloud-precipitation interactions in marine stratocumulus using LES. They concluded that under stronger wind speed, an enhanced surface moisture flux leads to a thickening of the cloud and stronger precipitation. Nuijens and Stevens (2012) investigated the equilibrium response of trade wind cumulus clouds to wind speed using LES. They found that at stronger winds, trade wind cumulus clouds are deeper but not more numerous or more energetic. Nuijens and Stevens (2012) identified the reason as an opposite response of the surface sensible heat and moisture fluxes to an increase in wind speed, which approximately maintains surface production of turbulence kinetic energy (TKE) and cloud base mass fluxes as wind speed increases.

Stratocumulus clouds respond to changes in environmental conditions on several timescales, ranging from hours to days (Schubert et al., 1979; Jones et al., 2014). The adjustment to environmental change on long (climatic) timescales has been investigated with multi-day simulations that converge towards a steady state (Caldwell and Bretherton, 2009; Xu et al., 2010; Blossey et al., 2013; Bretherton et al., 2013; van der Dussen et al., 2015). In this work, we investigate the response of non-precipitating, overcast marine stratocumulus clouds to different wind speeds, all else equal, in the course of a diurnal cycle. The goal is to identify and explain the dynamical processes by which wind speed acts on the evolution of BL growth, entrainment, decoupling, LWP, and cloud radiative effect (CRE). We also identify the role of buoyancyand shear-driven dynamics for BL growth, entrainment, decoupling, and liquid water path.

The investigation is motivated by observed trends towards higher wind speeds over the oceans. Young et al. (2011) identified, using satellite radar altimeter wave heights, a global increase in ocean surface wind speed in the period 19912008. Hande et al. (2012) found an increasing surface wind speed trend spanning nearly 4 decades in radiosonde data at a location in the Southern Ocean. Bertin et al. (2013) identified a significant increase in wave height (driven by wind speed) in the North Atlantic Ocean over the 20th century, and Servain et al. (2014) found an intensification of trade winds in the tropical Atlantic over the period 1964-2012 that accompanied an observed warming trend in SST. These trends in large-scale wind speed are not necessarily a consequence of climate change but could arise from internal cli- 
mate variability (Dobrynin et al., 2015). Additional motivation derives from projected changes in ocean wind speeds and wave heights in the course of the 21st century (McInnes et al., 2011; Hemer et al., 2013). Together with an associated cloud response, the observed and projected changes in large-scale wind speed would constitute a cloud-climate feedback mechanism with the potential to impact Earth's radiation budget, the formation of precipitation, and the effect of aerosol on clouds.

Here we conduct cloud-system resolving simulations with different large-scale wind speeds. The observed wind speed during the Second Dynamics and Chemistry of Marine Stratocumulus field study Research Flight 1 (DYCOMS-II RF01, Stevens et al., 2005) serves as a reference for a $\pm 25 \%$ faster and slower large-scale wind speed, respectively. We chose this variation because the associated variation in $10 \mathrm{~m}$ wind speed averaged over a diurnal cycle in our simulations $(-18 /+21 \%)$ is comparable to the peak values of the 1991-2008 change in ocean surface wind speed at the location of the northeastern Pacific coastal stratocumulus deck (Young et al., 2011). The different wind speeds drive different surface fluxes of sensible heat, moisture, and momentum in the simulations. We focus on the dynamical rather than the microphysical response of the stratocumulus-topped BL to changes in wind speed and excluded the effect of wind speed on surface aerosol production and loss by setting these terms to 0 . The simulations are initialized with $\mathrm{BL}$ properties, cloud properties, and dynamics that are consistent with DYCOMS-II RF01 observations. The simulations are hence a suitable framework for identifying and characterizing the mechanisms by which the stratocumulus-topped marine BL responds over a diurnal cycle to different wind speeds, all else equal. However, they do not represent a stratocumulus-topped marine BL in a future climate at different wind speeds, which would require initial and boundary conditions that are consistent with the chosen climate and wind speeds.

A key mechanism of the wind speed response of stratocumulus clouds is an increase or decrease of the surface moisture flux at higher or lower wind speed, respectively. This mechanism modulates cloud LWP, and thereby the response of the cloud to changes in aerosol concentration, as well as the propensity of the cloud to precipitate. In this work we focus on the non-precipitating stratocumulus state with a low precipitation susceptibility to aerosol concentration. The results of the simulations and the analysis are specific for this cloud state and the chosen environmental conditions.

A number of studies (e.g., Wang et al., 2008, 2012; Katzwinkel et al., 2012; Mellado et al., 2014) have investigated the effect of strong wind shear at the inversion on stratocumulus clouds. Such shear is often caused by a jump in large-scale wind speed and direction across the inversion, and differs qualitatively and quantitatively from shear that arises from the interaction of a constant large-scale wind speed with the surface and with the potential temperature gradient at the inversion. In this work, we only consider shear that is generated by a constant large-scale wind speed.

The text is organized as follows: Sect. 2 introduces the model and describes the spin-up runs and simulations. The final state of the spin-up runs (initial state of simulations) is compared with observations. Results are analyzed and discussed in Sect. 3. Conclusions are given in Sect. 4. Appendix A presents the nudging techniques used in the spinupruns to generate conditions in the initial state of the simulations that are consistent with observations, and in the simulations to maintain mean free-tropospheric potential temperature and water vapor profiles. Appendix B derives the BL total water budget equation, and Appendix $\mathrm{C}$ discusses the resolution dependence of the results.

\section{Model and simulations}

We use the Advanced Research WRF (ARW) model (Skamarock et al., 2008), which includes optional chemical and aerosol processes (WRF/Chem, Grell et al., 2005), with the modifications described in Kazil et al. (2011, 2014). Because we focus on the response of the stratocumulus-topped marine boundary to wind speed via the surface fluxes of sensible heat, moisture, and momentum, we disabled chemical reactions, sea spray aerosol emissions, and aerosol dry deposition. We decompose the total wind field into a residual component and a constant geostrophic component. The model was modified so that its dynamical core only operates on the residual wind field (Kazil et al., 2014). This is permitted because the Navier-Stokes equations are invariant under Galilean transformations. The simulation domain can hence be thought of as moving with the geostrophic wind over a stationary ocean surface, although the geographic location, which determines the Coriolis parameter and insolation, is held fixed. The residual wind field is nudged by Rayleigh damping towards 0 over a $250 \mathrm{~m}$ layer at the domain top. At the domain base, geostrophic wind acts on the residual wind field by the interaction of the total wind field with the surface: the surface fluxes of sensible heat, moisture, and horizontal momentum are calculated from the sum of the horizontal residual wind speed and the horizontal geostrophic wind speed at the lowest model level. The simulation domain is periodic in the horizontal dimensions, with a height of $1650 \mathrm{~m}$; it is located at $122^{\circ} \mathrm{W}, 31.5^{\circ} \mathrm{N}$. The SST is set to $291.5 \mathrm{~K}, 1 \mathrm{~K}$ below the SST used in Stevens et al. (2005). This value produced in the final state of the spin-up runs (initial state of the simulations) a surface sensible heat and moisture flux of 14 and $122 \mathrm{~W} \mathrm{~m}^{-2}$, respectively (Stevens et al., 2005 , give values of 15 and $115 \mathrm{~W} \mathrm{~m}^{-2}$, respectively). We use a surface pressure of $1017 \mathrm{hPa}$ and a surface large-scale divergence $\delta=3.75 \times 10^{-6} \mathrm{~s}^{-1}$ (Stevens et al., 2005). 
Table 1. List of spin-up runs.

\begin{tabular}{lclrll}
\hline Spin-up & $\begin{array}{c}\text { Domain size } \\
\left(\mathrm{km}^{2}\right)\end{array}$ & $\begin{array}{l}\mathrm{d} t \\
(\mathrm{~s})\end{array}$ & $\begin{array}{r}\mathrm{d} x=\mathrm{d} y \\
(\mathrm{~m})\end{array}$ & $\begin{array}{l}d \mathrm{z} \\
(\mathrm{m})\end{array}$ & Description \\
\hline$m$ & $30 \times 30$ & 1.5 & 150 & 15 & \\
$m_{\text {fine }}$ & $30 \times 30$ & 0.75 & 75 & 7.5 & Fine resolution \\
$l$ & $60 \times 60$ & 1.5 & 150 & 15 & \\
$l_{1: 5}$ & $60 \times 60$ & 1.5 & 75 & 15 & $1: 5$ aspect ratio \\
\hline
\end{tabular}

(a)

(c)
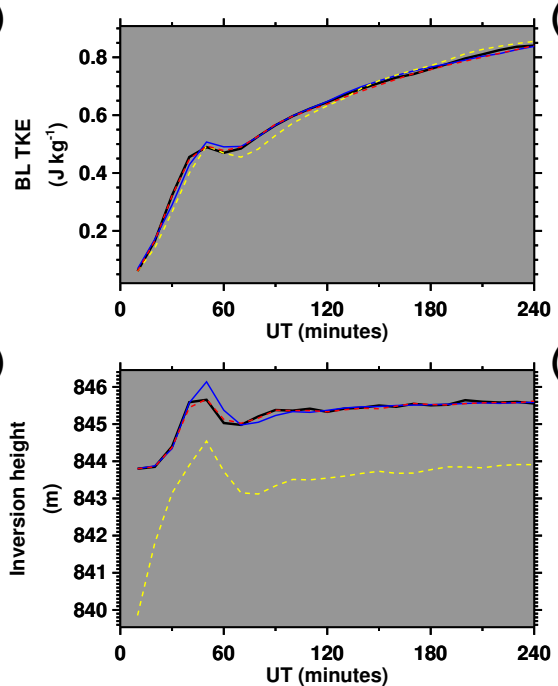

(b)

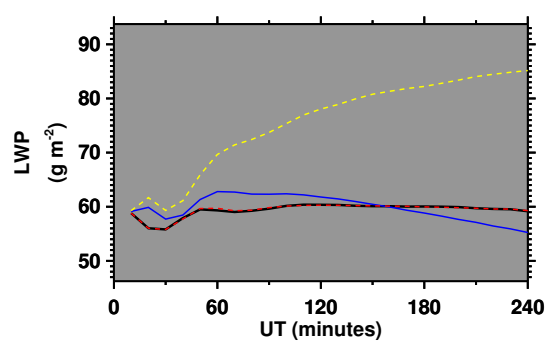

(d)

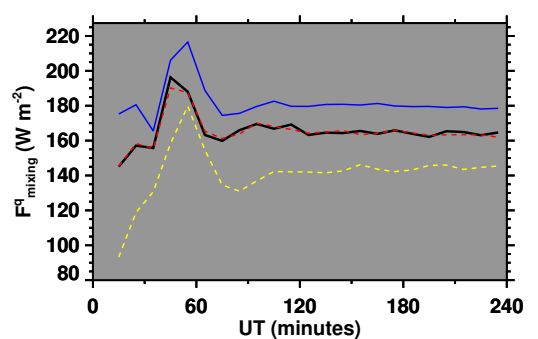

Figure 1. Time series from the spin-up runs $m$ (black), $m_{\text {fine }}$ (yellow), $l$ (red), $l_{1: 5}$ (blue). $F_{\text {mixing }}^{q}$ is defined in Eq. (2). Spin-up runs are listed in Table 1.

\subsection{Spin-up runs}

The list of the spin-up runs is given in Table 1. The runs are labeled with the letters $m$ (medium) and $l$ (large), which denote the domain size of 30 and $60 \mathrm{~km}$, respectively. The reference grid spacing is $\mathrm{d} x=\mathrm{d} y=150 \mathrm{~m}, \mathrm{~d} z \approx 15 \mathrm{~m}, \mathrm{~d} t=1.5 \mathrm{~s}$, where $\mathrm{dx}$ and $\mathrm{dy}$ are the horizontal grid constants, $\mathrm{d} z$ the vertical grid constant, and $\mathrm{d} t$ the time step. The spin-up run $m_{\text {fine }}$ uses double resolution in each dimension $(\mathrm{d} x=\mathrm{d} y=75 \mathrm{~m}$, $\mathrm{d} z \approx 7.5 \mathrm{~m}, \mathrm{~d} t=0.75 \mathrm{~s})$. The spin-up run $l_{1: 5}$ uses a reduced aspect ratio of $(1: 5)$, which is obtained by doubling horizontal resolution $(\mathrm{d} x=\mathrm{d} y=75 \mathrm{~m}, \mathrm{~d} z \approx 15 \mathrm{~m}, \mathrm{~d} t=1.5 \mathrm{~s})$.

\subsubsection{Initialization}

We prescribe altitude $(z)$ profiles of potential temperature $\theta(z)$ and total water content $q_{\mathrm{t}}(z)$ as specified for DYCOMS-II RF01 by Stevens et al. (2005) to initialize the spin-up runs. Cloud water $q_{\mathrm{c}}$ and rain water $q_{\mathrm{r}}$ are initialized with 0 values in the spin-up runs, hence the initial $q_{\mathrm{t}}$ is apportioned to $q_{\mathrm{v}}$. The spin-up runs use the reference geostrophic wind speed with a horizontal west-east component $U=7 \mathrm{~m} \mathrm{~s}^{-1}$ and a horizontal south-north component $V=-5.5 \mathrm{~m} \mathrm{~s}^{-1}$. The spin-up runs commence on
11 July 2001 at 00:00:00 UT and end at 04:00:00 UT, shortly after sunset. Nudging (Appendix A) maintains the mean potential temperature profiles and the aerosol number concentration of $300 \mathrm{mg}^{-1}$ throughout the simulation domain, and the total water profile in the free troposphere. Sedimentation and collision-coalescence of cloud droplets are disabled to prevent drizzle formation.

\subsubsection{Temporal evolution}

Figures 1 and 2 show the spin-up run time series. Resolution, aspect ratio, and domain size cause only small differences in BL TKE between the spin-up runs (Fig. 1a). LWP does not depend on domain size in the considered domain size range, but on resolution and aspect ratio (Fig. 1b). We discuss in the following the effect of resolution and aspect ratio, in the considered ranges, on the total water flux due to mixing across the inversion, and by extension, on LWP. The BL total water budget can be written as (Appendix B)

$$
\begin{aligned}
\frac{\mathrm{d} Q(t)}{\mathrm{d} t} & =F_{\text {precipitation }}^{q}+F_{\text {surface }}^{q}-F_{\text {entrainment }}^{q} \\
& -F_{\text {subsidence }}^{q}-F_{\text {mixing }}^{q} .
\end{aligned}
$$



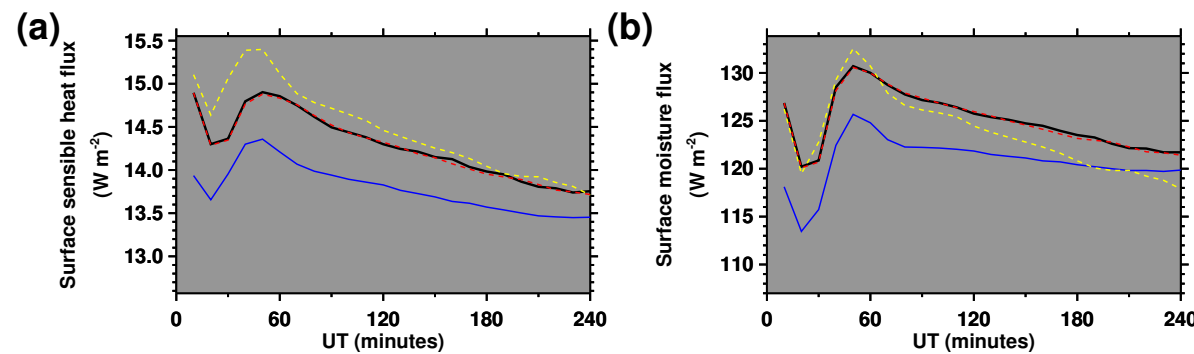

Figure 2. Time series from the spin-up runs $m$ (black), $m_{\text {fine }}$ (yellow), $l$ (red), $l_{1: 5}$ (blue). Spin-up runs are listed in Table 1.

$Q$ is the boundary layer mean total water mass path (vertically integrated total water mass per horizontal area). $F_{\text {precipitation }}^{q}$ is the surface water flux due to precipitation, $F_{\text {surface }}^{q}$ is the surface moisture flux, $F_{\text {entrainment }}^{q}$ the total water flux across the inversion due to changes in mean inversion height, $F_{\text {subsidence }}^{q}$ the total water flux across the inversion due to subsidence, and $F_{\text {mixing }}^{q}$ the total water flux across the inversion due resolved-scale and sub-grid-scale dynamics at the inversion, fluctuations in inversion height, and spurious mixing. The fluxes point up when positive, which, together with the level at which they are located (surface vs. inversion), explains their signs in Eq. (1). None of the water variables $\left(q_{\mathrm{v}}, q_{\mathrm{c}}, q_{\mathrm{r}}, q_{\mathrm{t}}\right)$ are nudged in the boundary layer (Appendix A), so that no nudging tendency needs to be accounted for in Eq. (1). Furthermore, $F_{\text {entrainment }}^{q}$ can be taken as 0 because mean potential temperature is nudged towards its initial profile (Appendix A), so that the mean inversion height exhibits only extremely small changes after approximately $90 \mathrm{~min}$ (Fig. 1c). $F_{\text {precipitation }}^{q}$ is 0 because sedimentation and collision-coalescence of cloud droplets are disabled in the spin-up period. Equation (1) can therefore be simplified and rearranged to

$F_{\text {mixing }}^{q}=F_{\text {surface }}^{q}-F_{\text {subsidence }}^{q}-\frac{\mathrm{d} Q(t)}{\mathrm{d} t}$.

Figure 1d shows the $F_{\text {mixing }}^{q}$ time series from the spin-up runs; in the calculation of $F_{\text {mixing }}^{q}, F_{\text {subsidence }}^{q}$ was approximated with its vertical component. Domain size has no effect on $F_{\text {mixing }}^{q}$ in the considered domain size range, but mixing depends on resolution and aspect ratio. Doubling resolution in all dimensions reduces $F_{\text {mixing }}^{q}$ by $\approx 20 \mathrm{~W} \mathrm{~m}^{-2}$, while reducing the aspect ratio from $1: 10$ to $1: 5$ increases $F_{\text {mixing }}^{q}$ by $\approx 15 \mathrm{~W} \mathrm{~m}^{-2}$ (Fig. 1d). The different $F_{\text {mixing }}^{q}$ change the temporal evolution of LWP in the spin-up runs (Fig. 1b). Relative to the spin-up runs $m$ and $l$, the spin-up run with doubled resolution in all dimensions $\left(m_{\text {fine }}\right)$ exhibits a higher (and increasing) LWP (Fig. 1b) because of lower mixing across the inversion (Fig. 1d). The spin-up run with a reduced aspect ratio $\left(l_{1: 5}\right)$ exhibits a lower (and decreasing) LWP because of higher mixing across the inversion. The causal attribution relies on the fact that the differences in resolution and aspect ratio between the runs $m, m_{\text {fine }}, l$, and $l_{1: 5}$ do not change $\mathrm{BL}$
TKE (Fig. 1a) and perturb the surface moisture flux much less (in the range $\approx 5 \mathrm{~W} \mathrm{~m}^{-2}$; Fig. $2 \mathrm{~b}$ ) than the total water flux across the inversion due to mixing (in the range of $\approx 35 \mathrm{~W} \mathrm{~m}^{-2}$; Fig. 1d). It is therefore the response of mixing across the inversion to resolution and aspect ratio that causes the different temporal evolution of LWP, rather than a response of the surface moisture flux or of boundary layer dynamics.

To summarize, higher resolution in all dimensions reduces mixing across the inversion and drying of the boundary layer. A lower aspect ratio enhances mixing across the inversion and drying of the boundary layer. These findings indicate counteracting effects of vertical and temporal resolution vs. horizontal resolution on mixing at the inversion. Consequently, a model-specific aspect ratio range exists within which resolution-dependent effects sufficiently compensate each other so that the model can produce results that are consistent with observations.

\subsubsection{Final state (initial state of simulations)}

Figures 3 and 4 compare the final state of the spin-up runs (initial state of the simulations) with observations from DYCOMS-II RF01 (Stevens et al., 2005). Liquid water potential temperature in the spin-up runs closely reproduces the observations (Fig. 3a) owing to nudging at all heights (Appendix A) towards the DYCOMS-II RF01 specification. Water variables $\left(q_{\mathrm{v}}, q_{\mathrm{c}}, q_{\mathrm{r}}, q_{\mathrm{t}}\right)$ are not nudged in the boundary layer. Total water observations are reproduced by the spin-up runs $m$ and $l$ (Fig. 3b) with no domain size dependence. Resolution and aspect ratio have a small impact on total water in the BL (Sect. 2.1.2): a higher resolution in all dimensions reduces drying of the $\mathrm{BL}$, and total water increases; a reduced aspect ratio enhances drying of the $\mathrm{BL}$, and total water decreases.

Cloud water is reproduced in part by the spin-up runs $m$ and $l$ (Fig. 3c), and cloud base cloud water is underestimated. This underestimation may be a consequence of absence of drizzle in the spin-up runs, caused by disabled sedimentation and collision-coalescence. While domain size has no effect on cloud water, resolution and aspect ratio do: a higher resolution in all dimensions reduces drying of the BL, and cloud water increases; a reduced aspect ratio enhances drying of 

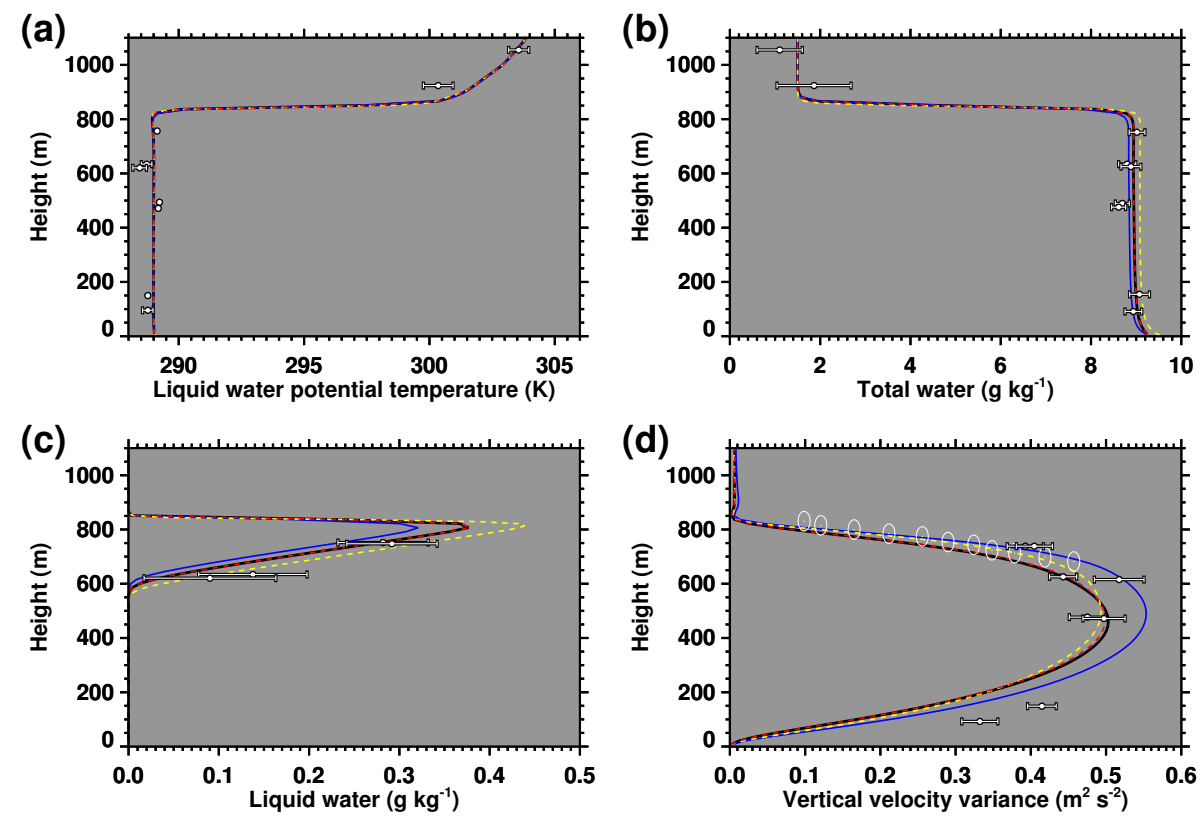

Figure 3. Final state of the spin-up runs (initial states of simulations). Mean final state of the spin-up run $m$ (black), $m_{\text {fine }}$ (yellow), $l$ (red), $l_{1: 5}$ (blue). Markers indicate DYCOMS-II RF01 in situ (solid with bar) and radar (ellipse-dot) data (Stevens et al., 2005). Spin-up runs are listed in Table 1.
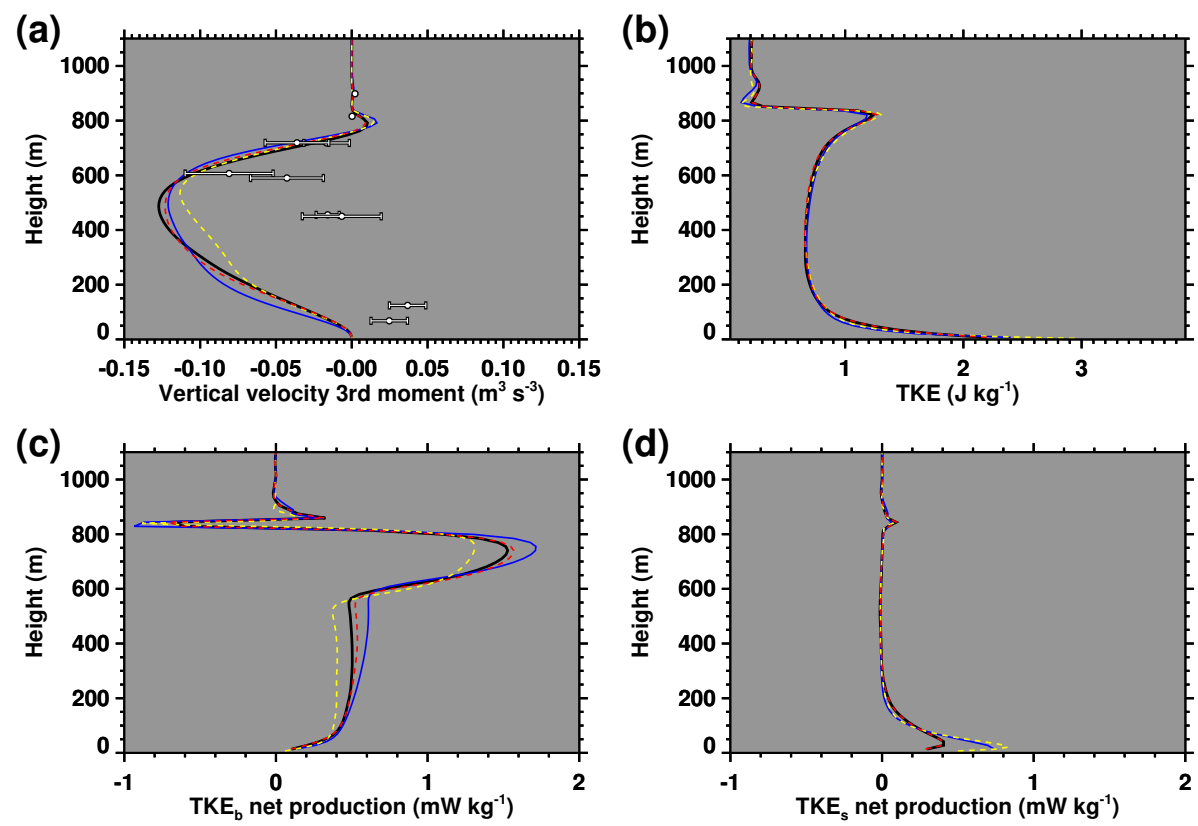

Figure 4. Final state of the spin-up runs (initial states of simulations). Mean final state of the spin-up run $m$ (black), $m_{\text {fine }}$ (yellow), $l$ (red), $l_{1: 5}$ (blue). Markers indicate DYCOMS-II RF01 in situ (solid with bar) data (Stevens et al., 2005). Spin-up runs are listed in Table 1.

the BL, and cloud water decreases (Sect. 2.1.2). The reduced aspect ratio spin-up run $l_{1: 5}$ misses the observed cloud water.

Vertical velocity variance $\left(w^{\prime 2}\right)$ exhibits a weak dependence on domain size and resolution and a stronger dependence on aspect ratio (Fig. 3d). The spin-up run $m_{\text {fine }}$ reproduces the observations best. The run $l_{1: 5}$ exhibits the highest vertical velocity variance values among the spin-up runs, and overestimates mid-BL observations. The spin-up runs miss two isolated data points in the lower BL. The third moment of vertical velocity $\left(w^{\prime 3}\right)$ exhibits a weak dependence on domain size, resolution, and aspect ratio, with negative values throughout the BL (Fig. 4a). The negative values and the 
Table 2. List of simulations. The superscripts,- 0 , and + denote low, reference, and high geostrophic wind speed, respectively (see Sect. 2.2). All three superscripts are used when referring to all three simulations in a set. Simulations that use prescribed, spatially homogenized surface sensible heat and moisture fluxes carry an overbar.

\begin{tabular}{llclrll}
\hline Simulation & Spin-up & $\begin{array}{r}\text { Domain size } \\
\left(\mathrm{km}^{2}\right)\end{array}$ & $\begin{array}{l}\mathrm{d} t \\
(\mathrm{~s})\end{array}$ & $\begin{array}{r}\mathrm{d} x=\mathrm{d} y \\
(\mathrm{~m})\end{array}$ & $\begin{array}{l}\mathrm{d} z \\
(\mathrm{~m})\end{array}$ & Description \\
\hline$M^{-, 0,+}$ & $m$ & $30 \times 30$ & 1.5 & 150 & 15 & \\
$M_{\text {fine }}^{-, 0,+}$ & $m_{\text {fine }}$ & $30 \times 30$ & 0.75 & 75 & 7.5 & Fine resolution \\
$M_{\text {dark }}^{-, 0,+}$ & $m$ & $30 \times 30$ & 1.5 & 150 & 15 & Perpetual night \\
$L^{-, 0,+}$ & $l$ & $60 \times 60$ & 1.5 & 150 & 15 & \\
$\bar{L}^{-, 0,+}$ & $l$ & $60 \times 60$ & 1.5 & 150 & 15 & Surface heat fluxes from $L^{-, 0,+}$ \\
$\bar{L}_{\text {buoy }}^{-, 0,+}$ & $l$ & $60 \times 60$ & 1.5 & 150 & 15 & Surface heat fluxes from $L^{-, 0,+}$, \\
& & & & & & no geostrophic wind \\
\hline
\end{tabular}

small differences between $w^{\prime 3}$ indicate a similar closed-cell BL dynamical structure throughout the spin-up runs, with broad, slow updrafts in the cell centers and narrow, stronger downdrafts along the cell periphery. The spin-up runs consistently underestimate observed $w^{\prime 3}$, which exhibits positive values in the lower BL. The observed positive values of $w^{\prime 3}$ in the lower BL indicate a stronger role of the surface sensible heat flux in driving dynamics in the observed BL relative to the spin-up runs.

The vertical distribution of TKE shows little dependence on domain size, resolution, and aspect ratio (Fig. 4b). In contrast, TKE production by buoyancy weakens at higher resolution and strengthens at a reduced aspect ratio (Fig. 4c). Because the TKE vertical profiles are nearly identical (Fig. 4b), the higher-resolution spin-up runs dissipate TKE at a slower pace, and the reduced aspect ratio spin-up runs at a faster pace. Buoyancy production of TKE dominates dynamics of the boundary layer except in the lowermost $100 \mathrm{~m}$, where shear production of TKE is strongest (Fig. 4d). Near-surface production of TKE by shear increases at both higher resolution and reduced aspect ratio.

The comparison of total water, cloud water, and vertical velocity variance with DYCOMS-II RF01 observations (Fig. 3b-d) implies that at the aspect ratio of $1: 10$, competing effects in the model approximately compensate each other. The smaller aspect ratio of $1: 5$ produces a less favorable comparison with observations, owing to mixing at the inversion and associated excessive drying of the boundary layer. While recognizing uncertainty in the observations, we use the aspect ratio of $1: 10$ in the simulations in this work.

\subsection{Simulations}

The simulations are listed in Table 2; they are labeled with the letters $M$ (medium) and $L$ (large) which denote domain size. The simulations are initialized with the final state of the spin-up runs, on 11 July 2001 at 04:00:00 UT, and end on 12 July 2001 at 04:00:00 UT.
The reference resolution is $\mathrm{d} x=\mathrm{d} y=150 \mathrm{~m}, \mathrm{~d} z \approx 15 \mathrm{~m}$, $\mathrm{d} t=1.5 \mathrm{~s}$. Select simulations were conducted with double resolution $(\mathrm{d} x=\mathrm{d} y=75 \mathrm{~m}, \mathrm{~d} z \approx 7.5 \mathrm{~m}, \mathrm{~d} t=0.75 \mathrm{~s})$. We used the following geostrophic wind speeds: a low wind speed $\left(U=5.25 \mathrm{~m} \mathrm{~s}^{-1}, V=-4.13 \mathrm{~m} \mathrm{~s}^{-1}\right)$, the DYCOMSII RF01 wind speed $\left(U=7.00 \mathrm{~m} \mathrm{~s}^{-1}, V=-5.50 \mathrm{~m} \mathrm{~s}^{-1}\right.$, Stevens et al., 2005), and a high wind speed $\left(U=8.75 \mathrm{~m} \mathrm{~s}^{-1}\right.$, $V=-6.88 \mathrm{~m} \mathrm{~s}^{-1}$ ). High (low) geostrophic wind speed is indicated with $\mathrm{a}+(-)$ superscript in the simulation symbol, respectively; the DYCOMS-II RF01 geostrophic wind speed is denoted with the superscript 0 . We conducted the following sets of simulations.

- To identify the effect of insolation over the diurnal cycle in the simulations $\mathrm{M}^{-, 0,+}$, we ran simulations with perpetual night conditions $\left(M_{\text {dark }}^{-, 0,+}\right)$. Perpetual night conditions were implemented by disabling shortwave radiation.

- To identify the effect of buoyant and shear production of TKE in the simulations $L^{-, 0,+}$, we conducted the simulations $\bar{L}_{\text {buoy }}^{-, 0,+}$ with 0 geostrophic wind speed, driven by spatially homogenized surface sensible heat and moisture fluxes from the simulations $\mathrm{L}^{-, 0,+}$, respectively. To factor out the small effect of spatial homogenization on boundary layer properties, we conducted the simulations $\bar{L}^{-, 0,+}$. These are otherwise identical to $L^{-, 0,+}$ but are driven with the spatially homogenized surface sensible heat and moisture fluxes from $L^{-, 0,+}$. In $\bar{L}^{-, 0,+}$ (as in $L^{-, 0,+}$ ), dynamics is driven by both buoyant production of TKE and by shear production of TKE due to the geostrophic wind. In $\bar{L}_{\text {buoy }}^{-, 0,+}$, dynamics is driven only by buoyant production of TKE. The effect of buoyant and shear production of TKE is discussed based on the comparison of $\bar{L}^{-, 0,+}$ and $\bar{L}_{\text {buoy }}^{-, 0,+}$.

Sedimentation and collision-coalescence of cloud droplets were allowed to proceed in the simulations. 
(a)

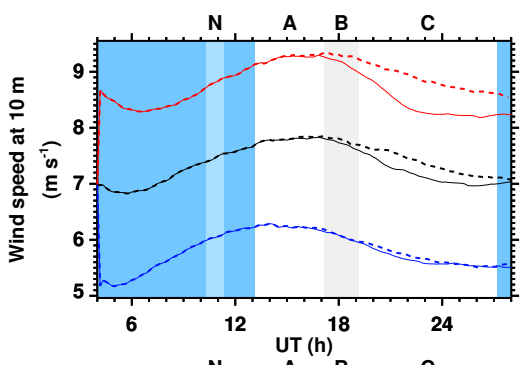

(c)

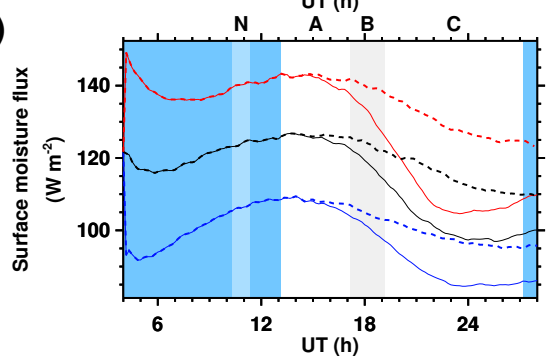

(b)

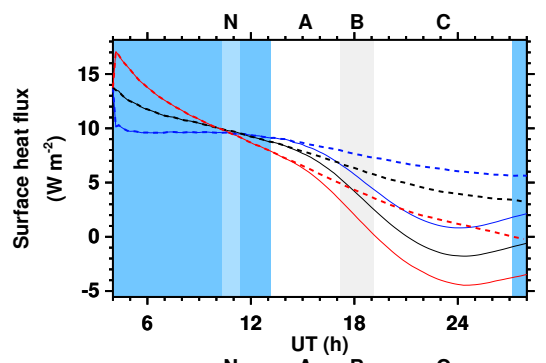

(d)

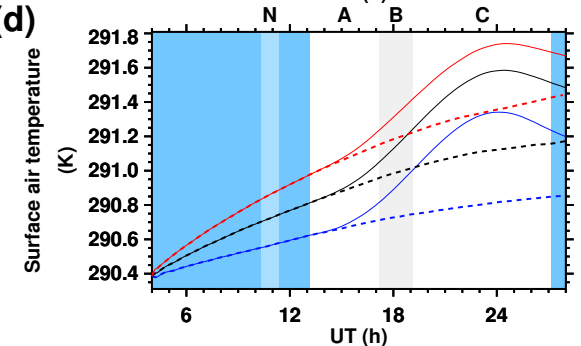

Figure 5. Wind speed and the diurnal cycle. Time series from simulations $M^{-}$(blue), $M^{0}$ (black), $M^{+}$(red), solid curves, and from simulations $M_{\text {dark }}^{-}$(blue), $M_{\text {dark }}^{0}$ (black), $M_{\text {dark }}^{+}$(red), dashed curves. Blue shading indicates nighttime. The time periods A, B, C, and N are highlighted to facilitate the discussion.

\section{Results and discussion}

\subsection{Wind speed and the diurnal cycle}

This section identifies and explains the mechanisms by which wind speed acts on the evolution of boundary layer growth, entrainment, decoupling, LWP, and CRE in the course of the diurnal cycle. Figures 5-10 show time series from the simulations $M^{-, 0,+}$, which have a diurnal insolation cycle, and from the perpetual night simulations $M_{\mathrm{dark}}^{-, 0,+}$. The time periods A, B, C, and $\mathrm{N}$ are highlighted to facilitate the discussion. Period A, which commences at sunrise, is characterized by a peak in LWP (Fig. 8a), period B by a peak in cloud radiative effect (Fig. 8c), and period C, which ends at sunset, by a peak in decoupling (Fig. 7b). The period $\mathrm{N}$ covers $1 \mathrm{~h}$ during nighttime (10:20-11:20 UT) when the surface sensible heat flux in the different wind speed simulations is nearly identical (Fig. 5b), so that its role as a dynamical driver can be factored out from the analysis.

\subsubsection{Surface sensible heat and moisture fluxes and decoupling}

Figure 5a shows the wind speed $10 \mathrm{~m}$ above sea level. In the simulations with a diurnal cycle $\left(M^{-, 0,+}\right)$, the $10 \mathrm{~m}$ wind speed is suppressed during daytime relative to the simulations with perpetual night conditions $\left(M_{\text {dark }}^{-, 0,+}\right)$. This daytime suppression increases with wind speed and is a result of daytime decoupling.

All else equal but wind speed, the surface sensible heat and moisture fluxes would increase (decrease) with higher (lower) wind speed. This is not the case for the surface sensible heat flux: after an initial adjustment (04:00-10:50 UT), the surface sensible heat flux is anti-correlated with wind speed (Fig. 5b). Wind speed and surface moisture flux are, however, correlated throughout the simulations (Fig. 5c). Both surface sensible heat and moisture fluxes are suppressed during daytime in the simulations with a diurnal cycle $\left(M^{-, 0,+}\right)$, relative to those without $\left(M_{\text {dark }}^{-, 0,+}\right)$.

To understand the wind speed response of the surface sensible heat and moisture fluxes, surface layer temperature and water vapor need to be considered in addition to wind speed. The surface sensible heat $\left(F_{\text {surface }}^{\mathrm{h}}\right)$ and moisture $\left(F_{\text {surface }}^{q}\right)$ fluxes are calculated from the total horizontal wind speed $|\boldsymbol{U}+\boldsymbol{V}|$ in the surface layer:

$F_{\text {surface }}^{\mathrm{h}} \propto \Delta T|\boldsymbol{U}+\boldsymbol{V}|_{\text {surface }}$,

$F_{\text {surface }}^{q} \propto \Delta q_{\mathrm{v}}|\boldsymbol{U}+\boldsymbol{V}|_{\text {surface }}$.

$\boldsymbol{U}$ and $\boldsymbol{V}$ are the component vectors of the horizontal wind speed in the west-east and south-north directions, respectively; $\Delta T$ is the difference between the SST and the surface layer air temperature; $\Delta q_{\mathrm{v}}$ is the difference between the saturation water vapor mixing ratio at the SST and the surface layer water vapor mixing ratio. The drivers of the surface sensible heat and moisture fluxes are hence surface layer temperature, surface layer water vapor, and surface wind speed.

Figures 5d and 6a show the evolution of surface layer temperature and water vapor. The surface layer becomes warmer (Fig. 5d) and moister (Fig. 6a) with increasing wind speed. This surface warming and moistening counteracts the effect of higher wind speed on the surface sensible heat and moisture fluxes. In the case of the surface sensible heat flux (Fig. 5b) the effect of warming outbalances $(t \gtrsim 10: 50 \mathrm{UT})$ the effect of higher wind speed, and the surface sensible heat flux becomes suppressed at higher wind speed. The suppres- 

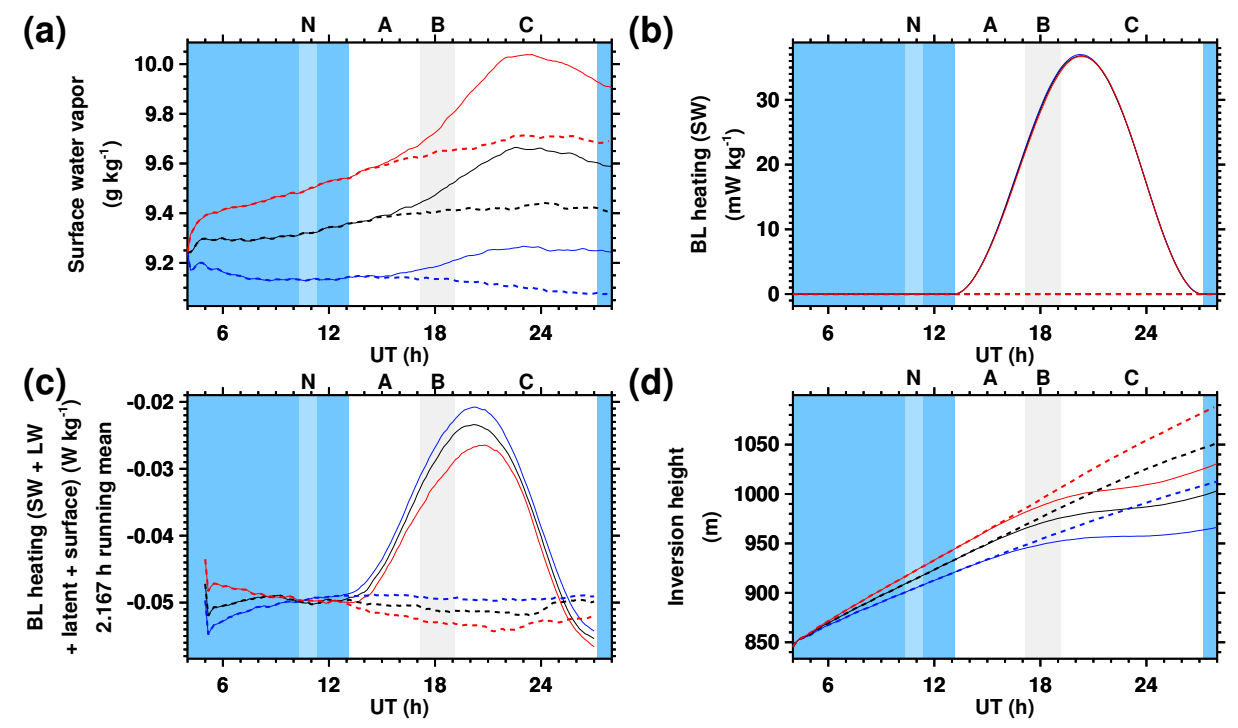

Figure 6. Wind speed and the diurnal cycle. Time series from simulations $M^{-}$(blue), $M^{0}$ (black), $M^{+}$(red), solid curves, and from simulations $M_{\text {dark }}^{-}$(blue), $M_{\text {dark }}^{0}$ (black), $M_{\text {dark }}^{+}$(red), dashed curves. A low-pass (running mean) filter was applied where indicated to reduce noise.

sion of the surface sensible heat flux by surface warming is magnified by insolation in the simulations with a diurnal cycle $\left(M^{-, 0,+}\right)$, relative to those with perpetual night conditions $\left(M_{\text {dark }}^{-, 0,+}\right)$. The surface moisture flux (Fig. 5c) is also reduced during daytime in the simulations with a diurnal cycle $\left(M^{-, 0,+}\right)$, relative to those with perpetual night conditions $\left(M_{\text {dark }}^{-, 0,+}\right)$. We will first focus on the general surface warming and moistening with increasing wind speed and then discuss daytime warming and decoupling.

Figure $6 \mathrm{~b}$ shows the heating of the boundary layer from absorption of shortwave radiation, and Fig. 6c shows the heating of the boundary layer from short- and longwave radiation, latent heat release and uptake, and the surface sensible heat flux. Following the initial adjustment (04:00-10:50 UT), higher wind speed acts to cool, while lower wind speed acts to warm the boundary layer via the combined action of these mechanisms. The general warming of the surface layer with wind speed (and of the boundary layer as a whole, not shown) therefore arises by the remaining mechanism, enhanced entrainment of warm air from the free troposphere at higher wind speed. Indeed, the boundary layer grows faster and thereby entrains more FT air at higher wind speed: Fig. $6 \mathrm{~d}$ shows the temporal evolution of the mean inversion height $\bar{z}_{\mathrm{i}}$ as a function of wind speed, and Fig. $7 \mathrm{a}$ the associated mean entrainment velocity

$w_{\mathrm{e}}=\frac{\mathrm{d} \bar{z}_{\mathrm{i}}}{\mathrm{d} t}+\delta \cdot \bar{z}_{\mathrm{i}}$.

The general moistening of the surface layer with wind speed (Fig. 6a) is caused by a higher surface moisture flux (Fig. 5c) in response to higher surface wind speed (Fig. 5a) and in part by greater dynamical decoupling of the cloud layer and the surface at higher wind speed. We quantify decoupling with the decoupling index

$\frac{\bar{z}_{\mathrm{b}}-\bar{z}_{\mathrm{LCL}}}{\bar{z}_{\mathrm{b}}}$,

where $\bar{z}_{\mathrm{b}}$ is the mean cloud base altitude and $\bar{z}_{\mathrm{LCL}}$ the mean lifting condensation level altitude. Decoupling renders vertical transport of moisture from the surface to cloud base less efficient. Since decoupling increases with wind speed (Fig. 7b), it contributes to higher surface moisture at higher wind speed.

During daytime, the surface layer is warmer and the boundary layer more decoupled in the simulations $\mathrm{M}^{-, 0,+}$ relative to the simulations $M_{\text {dark }}^{-, 0,+}$ (Figs. $5 \mathrm{~d}$ and $7 \mathrm{~b}$ ). The mechanism underlying daytime decoupling (Turton and Nicholls, 1987) has been documented (Wood, 2012, and references therein). The daytime surface warming is caused by insolation rather than by entrainment warming, because entrainment weakens during daytime in the simulations $M^{-, 0,+}$ relative to $M_{\text {dark }}^{-, 0,+}$ (Fig. 7a). In response to the warmer surface layer, the daytime surface sensible heat flux is suppressed in the simulations $M^{-, 0,+}$ relative to $M_{\text {dark }}^{-, 0,+}$. Daytime decoupling is also clearly apparent in surface layer moisture (Fig. 6a) in the diurnal cycle simulations $M^{-, 0,+}$ when compared with the perpetual night simulations $M_{\text {dark }}^{-, 0,+}$ : the simulations $M^{-, 0,+}$ produce a moister daytime surface layer relative to the simulations $M_{\text {dark }}^{-, 0,+}$, despite a lower daytime surface moisture flux (Fig. 5c). This enhanced moistening of the surface layer suppresses the daytime surface moisture flux (Fig. 5c) via Eq. (4). 
(a)

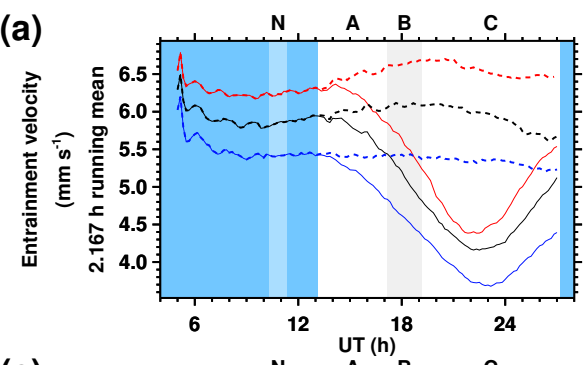

(c)

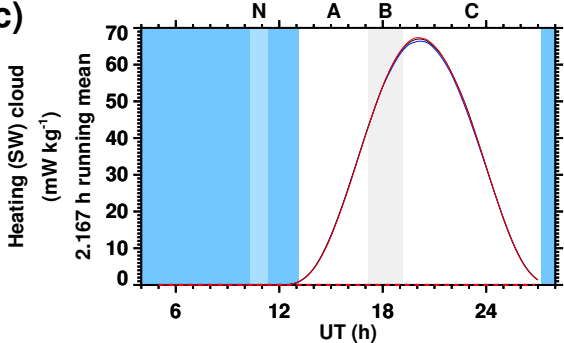

(b)

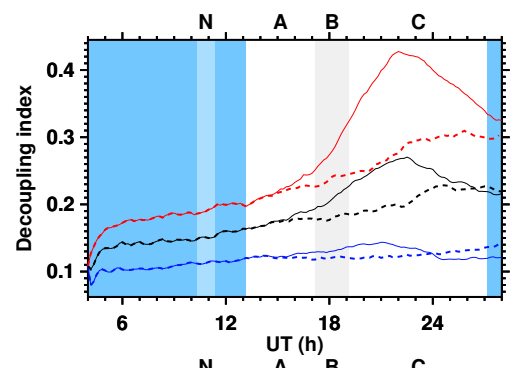

(d)

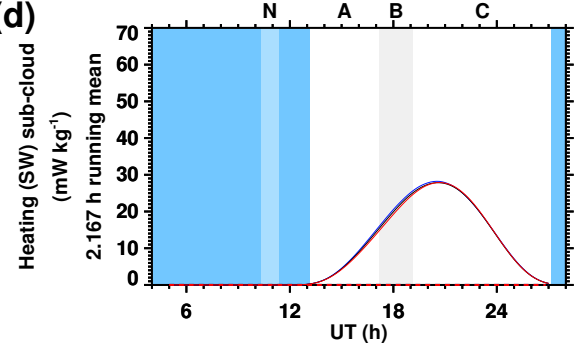

Figure 7. Wind speed and the diurnal cycle. Time series from simulations $M^{-}$(blue), $M^{0}$ (black), $M^{+}$(red), solid curves, and from simulations $M_{\text {dark }}^{-}$(blue), $M_{\text {dark }}^{0}$ (black), $M_{\text {dark }}^{+}$(red), dashed curves. A low-pass (running mean) filter was applied where indicated to reduce noise.

\subsubsection{Wind speed as driver of boundary layer growth and entrainment}

Here we identify the mechanism by which higher wind speed drives faster boundary layer growth and stronger entrainment. Since increasing wind speed results in higher LWP (Fig. 8a), one may be led to assume that at higher wind speed, stronger cloud top longwave emissions drive additional TKE production, which in turn drives stronger entrainment. However, LW cooling of stratocumulus clouds becomes insensitive to LWP for $50 \mathrm{~g} \mathrm{~m}^{-2} \lesssim \mathrm{LWP} \leq 250 \mathrm{~g} \mathrm{~m}^{-2}$ (Petters, 2009). We will show that wind speed drives faster boundary layer growth and stronger entrainment by enhancing TKE production from latent heat release in cloud layer updrafts. Figure 11 shows LW heating (a), latent heating (b), and TKE net production by buoyancy (c) and shear (d) as functions of the normalized height $z / \bar{z}_{\mathrm{i}}$, averaged over the period N (10:20-11:20UT) from the simulations $M^{-, 0,+}$, separated by updrafts and downdrafts. The surface sensible heat flux is nearly identical in the different wind speed simulations in period $\mathrm{N}$ (Fig. 5b), and its role can be factored out from the analysis. The conclusions are valid at later times, because increasing wind speed suppresses the surface sensible heat flux following the period N (Fig. 5b), so that the surface sensible heat flux cannot account for higher boundary layer growth and stronger entrainment. The layers $L_{1}$ $\left(0.925 \leq z / \bar{z}_{\mathrm{i}}<1.0375\right)$ and $L_{2}\left(0.625 \leq z / \bar{z}_{\mathrm{i}}<0.925\right)$ are highlighted to facilitate the discussion. Layer $\mathrm{L}_{1}$ contains most of the LW cooling (Fig. 11a) and some latent heating and cooling (Fig. 11b). In layer $L_{2}$, latent heating/cooling dominates over LW heating/cooling.

LW heating/cooling does not respond to wind speed (Fig. 11a). Latent cooling of downdrafts in layer $L_{1}$ shows no systematic response to wind speed, while latent heating of updrafts in layer $L_{1}$ shows a weak increase with wind speed (Fig. 11b). This absence of a clear wind speed signal in layer $L_{1}$ turns the focus to layer $L_{2}$. In its lower part, latent heating increases more in the updrafts than latent cooling in the downdrafts in response to increasing wind speed. More importantly, TKE net production by buoyancy shows a positive response to wind speed only in the updrafts of layer $L_{2}$ (Fig. 11c). Since in layer $L_{2}$, latent heating/cooling dominates over LW heating/cooling, we deduce that wind speed drives boundary layer growth and entrainment by boosting latent heat release and buoyant production of TKE in cloud updrafts, in response to the higher surface moisture flux at higher wind speed. This mechanism also proceeds in the initial stage of the transition from a stratocumulus to a shallow cumulus cloud state, in which an increasing SST drives a stronger surface moisture flux, which in turn increases TKE production by latent heat release at cloud level and thereby entrainment (Bretherton, 1992; Krueger et al., 1995a, b; Bretherton and Wyant, 1997; Wyant et al., 1997). Here it does, however, not initiate the dissipation of the stratocumulus deck.

Figure 11d shows TKE net production by shear. Near the surface, shear drives a stronger circulation at higher wind speed. At the inversion, in layer $L_{1}$, shear also contributes to a stronger circulation with increasing wind speed. This latter contribution could enhance entrainment at higher wind speed, although it is clearly weaker than the increase with wind speed of TKE net production from buoyancy in updrafts of layer $L_{2}$ (Fig. 11c). The role of buoyancy and shear production of TKE in driving circulation and the evolution of the boundary layer will be discussed in Sect. 3.2, where we show 
(a)

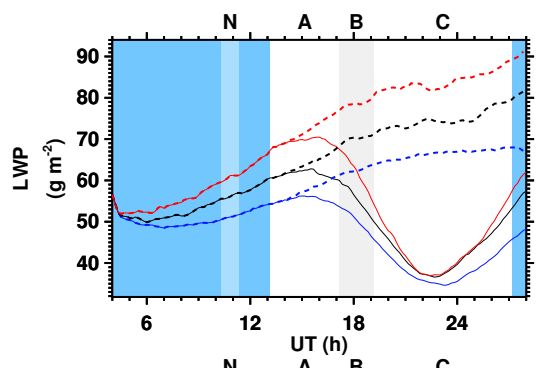

(c)

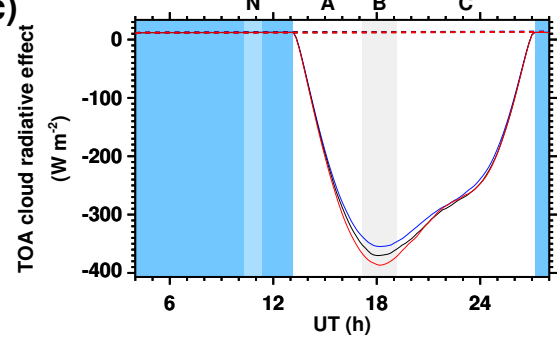

(b)

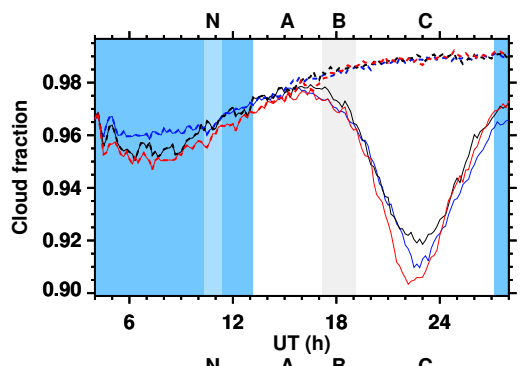

(d)

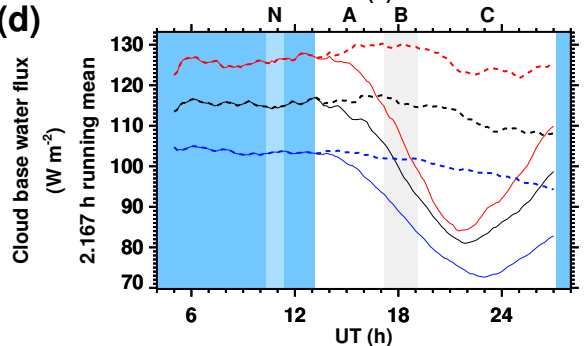

Figure 8. Wind speed and the diurnal cycle. Time series from simulations $M^{-}$(blue), $M^{0}$ (black), $M^{+}$(red), solid curves, and from simulations $M_{\text {dark }}^{-}$(blue), $M_{\text {dark }}^{0}$ (black), $M_{\text {dark }}^{+}$(red), dashed curves. A low-pass (running mean) filter was applied where indicated to reduce noise.

that buoyant production of TKE is the fundamental mechanism of enhanced boundary layer growth and entrainment at higher wind speed.

\subsubsection{Wind speed and LWP, cloud fraction, and CRE}

Figure 8a-c show LWP, cloud fraction, and total (shortwave + longwave) CRE from the simulations $M^{-, 0,+}$ and $M_{\text {dark }}^{-, 0,+}$. LWP increases with wind speed (Fig. 8a) throughout the perpetual night simulations $\left(M_{\text {dark }}^{-, 0,+}\right)$, via the wind speed enhancement of the surface moisture flux (Fig. 5c). Insolation suppresses LWP during daytime in the simulations $M^{-, 0,+}$, which creates a LWP peak in the early morning hours (period A). Both LWP morning peak and daytime suppression increase with wind speed. Wind speed hence accentuates the diurnal LWP cycle by expanding the morningafternoon contrast. Cloud fraction (Fig. 8b) is suppressed during daytime by insolation as well. At higher resolution, daytime suppression of cloud fraction becomes smaller and less dependent on wind speed, while our other findings remain unaffected (Appendix C).

LWP, cloud fraction, and insolation co-determine the CRE (Fig. 8c). Neither factor dominates, and CRE peaks in period B, following the morning LWP peak (period A; Fig. 8a) but before the midday insolation peak (early period C; Fig. 6b). At the time of the CRE peak, LWP is enhanced at higher wind speed (Fig. 8a); hence the CRE strengthens with wind speed. In the course of the day, however, LWP (Fig. 8a) and cloud fraction (Fig. 8b) fall more rapidly at higher wind speed, and afternoon CRE values (period C) at high wind speed approach those of the low and reference wind speed simulations.
Table 3 gives the total (shortwave + longwave) top-ofatmosphere CRE averaged over the $24 \mathrm{~h}$ duration of the simulations, from the simulations $M^{-, 0,+}$ with the reference resolution, and from the simulations $M_{\text {fine }}^{-, 0,+}$ with double resolution in each dimension. The diurnally averaged CRE increases with wind speed at both resolutions. However, with increasing wind speed, CRE becomes less sensitive to wind speed. The reason is the stronger suppression of LWP in the afternoon at higher wind speed, which also suppresses the CRE (Fig. 8c). Notably, both the diurnally averaged CRE and its response to wind speed depend on resolution. The effect of resolution is documented in Appendix C.

\subsubsection{Wind speed enhanced daytime suppression of LWP}

We will now examine the enhanced daytime LWP suppression at higher wind speed in the simulations $M^{-, 0,+}$ (Fig. 8a). We will conclude that during daytime, despite higher decoupling and a reduced moisture flux in cloud base updrafts at higher wind speed, buoyant TKE production in cloud-level updrafts increases with wind speed and drives additional entrainment, causing stronger cloud water evaporation and LWP reduction. We shall first discuss daytime decoupling and proceed to the action of wind speed.

Insolation in the simulations $M^{-, 0,+}$ warms the cloud layer (Fig. 7c) more than the sub-cloud layer (Fig. 7d), because absorption by cloud water and water vapor at cloud level reduces the amount of shortwave radiation reaching the sub-cloud layer. The warming of the cloud layer reduces LWP (Fig. 8a) and stabilizes the boundary layer. Daytime TKE production falls in the simulations $M^{-, 0,+}$ (Fig. 9b) mainly as a result of reduced TKE production by buoyancy 
Table 3. Total (shortwave + longwave) top-of-atmosphere cloud radiative effect $\left(\mathrm{W} \mathrm{m}^{-2}\right)$ averaged over the $24 \mathrm{~h}$ duration of the simulations. Simulations are given in parentheses (Table 2).

\begin{tabular}{llll}
\hline Resolution & Low wind speed & Reference wind speed & High wind speed \\
\hline $\mathrm{d} x=\mathrm{d} y=150 \mathrm{~m}, \mathrm{~d} z \approx 15 \mathrm{~m}, \mathrm{~d} t=1.5 \mathrm{~s}$ & $-130.6\left(M^{-}\right)$ & $-135.1\left(M^{0}\right)$ & $-137.9\left(M^{+}\right)$ \\
$\mathrm{d} x=\mathrm{d} y=75 \mathrm{~m}, \mathrm{~d} z \approx 7.5 \mathrm{~m}, \mathrm{~d} t=0.75 \mathrm{~s}$ & $-142.0\left(M_{\text {fine }}^{-}\right)$ & $-148.7\left(M_{\text {fine }}^{0}\right)$ & $-151.1\left(M_{\text {fine }}^{+}\right)$ \\
\hline
\end{tabular}
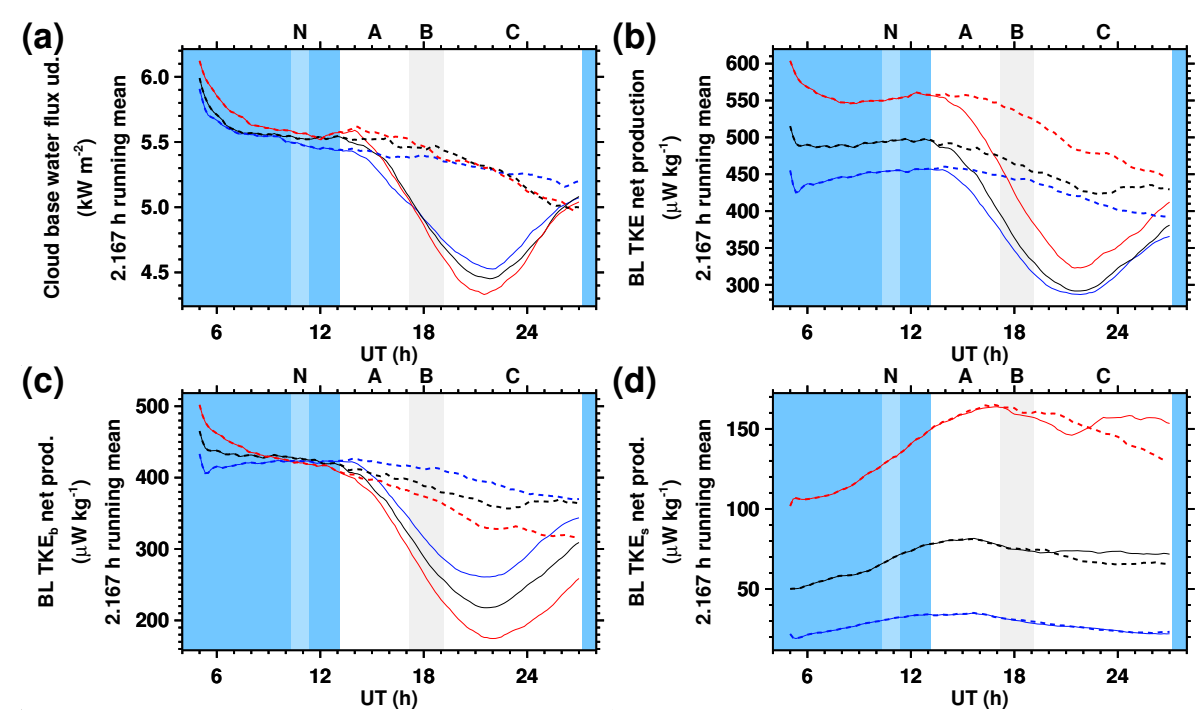

Figure 9. Wind speed and the diurnal cycle. Time series from simulations $M^{-}$(blue), $M^{0}$ (black), $M^{+}$(red), solid curves, and from simulations $M_{\text {dark }}^{-}$(blue), $M_{\text {dark }}^{0}$ (black), $M_{\text {dark }}^{+}$(red), dashed curves. The cloud base water flux in updrafts is given per horizontal surface area of the domain. A low-pass (running mean) filter was applied where indicated to reduce noise.

(Fig. 9c), as TKE production by shear varies only weakly during daytime (Fig. 9d). The resulting warmer (Fig. 5d), more weakly driven (Fig. 9b), and more decoupled (Fig. 7b) daytime circulation in the simulations $M^{-, 0,+}$ suppresses surface wind speed (Fig. 5a) and the surface sensible heat and moisture flux (Fig. 5b and c) relative to the simulations $M_{\text {dark }}^{-, 0,+}$. Still, a higher wind speed drives a higher surface moisture flux in the simulations $M^{-, 0,+}$ (Fig. 5c), as well as a higher cloud base moisture flux (Fig. 8d). However, the moisture flux in cloud base updrafts decreases with increasing wind speed in the simulations $M^{-, 0,+}$ during the daytime period B and C (Fig. 9a). Nonetheless, TKE production by buoyancy in cloud layer updrafts increases with wind speed during the period B and C (Fig. 10a) and is the only buoyancy-driven TKE production term that increases with wind speed at all times (Fig. 10). Hence, wind speed drives boundary layer growth and entrainment by boosting buoyant production of TKE in cloud updrafts even in decoupled daytime conditions, when stronger decoupling at higher wind speed leads to a reduced moisture flux in cloud base updrafts. Although the buoyant production of TKE due to latent heat release in cloud layer updrafts drives additional entrainment at higher wind speed, the associated formation of cloud water is insufficient to compensate cloud water evaporation from higher entrainment drying and warming at higher wind speed, and LWP is progressively suppressed during daytime as wind speed increases (Fig. 8a). This mechanism could potentially assist in the transition from stratocumulus to shallow cumulus along a gradient in SST (Bretherton, 1992; Bretherton and Wyant, 1997; Wyant et al., 1997).

\subsection{Buoyancy- and shear-driven dynamics}

This section discusses the role of buoyancy- and shear-driven dynamics (due to the geostrophic wind) for the properties and evolution of the boundary layer. The goal is to identify the role of buoyancy- and shear-driven dynamics in boundary layer growth and entrainment at different wind speeds, and the mechanism by which shear due to the geostrophic wind modulates decoupling in the course of the diurnal cycle. We limit the discussion to phenomenological aspects of buoyancy and shear effects, noting that the interaction of buoyancy- and shear-driven dynamics and the underlying mechanisms and causal relationships lend themselves to indepth investigation beyond the scope of this work. 

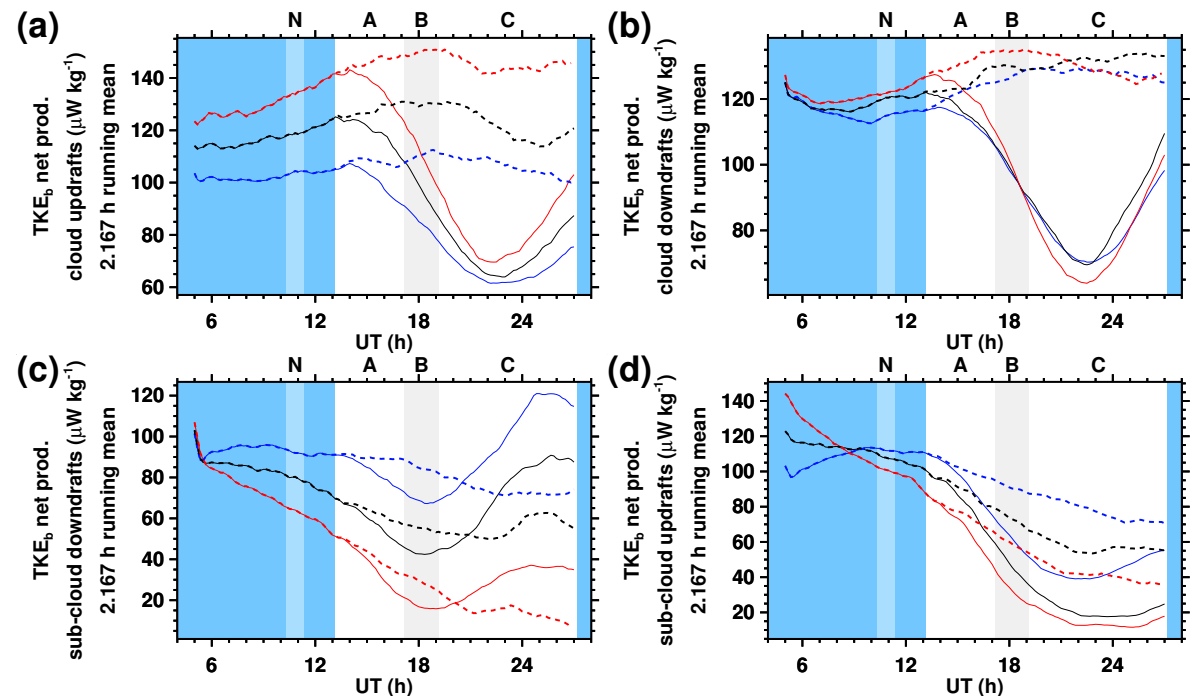

Figure 10. Wind speed and the diurnal cycle. Time series from simulations $M^{-}$(blue), $M^{0}$ (black), $M^{+}$(red), solid curves, and from simulations $M_{\text {dark }}^{-}$(blue), $M_{\text {dark }}^{0}$ (black), $M_{\text {dark }}^{+}$(red), dashed curves. TKE production rates are given per total boundary layer air mass. A low-pass (running mean) filter was applied where indicated to reduce noise.

(a)

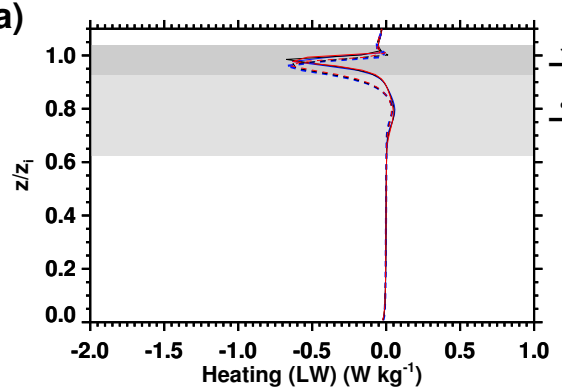

(c)

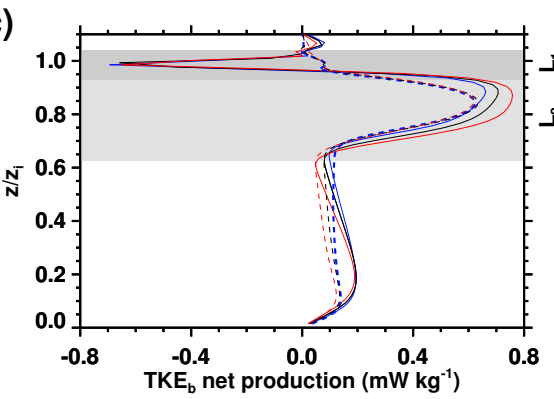

(b)

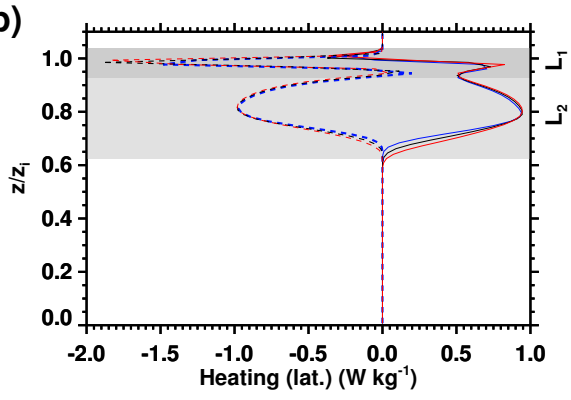

(d)

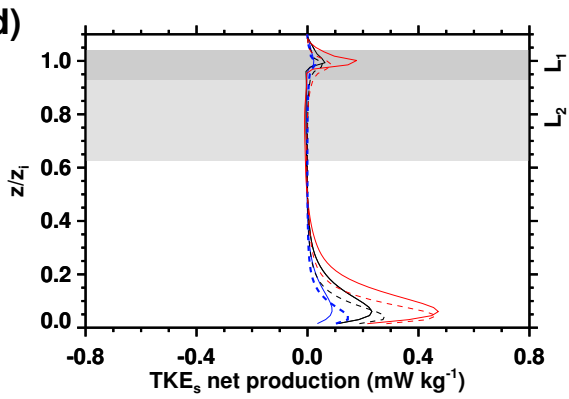

Figure 11. Longwave heating (a), latent heating (b), and TKE net production from buoyancy (c) and shear (d), averaged over the period $\mathrm{N}$ (10:20-11:20 UT) from the simulations $M^{-}$(blue), $M^{0}$ (black), $M^{+}$(red). Solid curves denote values from updrafts, dashed curves values from downdrafts. Updraft and downdraft values are air mass weighted sums over the updraft or downdraft locations at each level, respectively, normalized by the level air mass.

\subsubsection{Dynamical support of boundary layer growth and entrainment}

Figures 12-14 show time series from the simulations $\bar{L}_{\text {buoy }}^{-, 0,+}$ and $\bar{L}^{-, 0,+}$. The $10 \mathrm{~m}$ wind speed in the simulations $\bar{L}_{\text {buoy }}^{-, 0,+}$ has no geostrophic component and is hence lower than in the simulations $\bar{L}^{-, 0,+}$ (Fig. 12a), while as prescribed, the sur- face sensible heat and moisture fluxes are identical (Fig. 12b and c). The action of buoyancy- and shear-driven dynamics appears in the decoupling index, inversion height, entrainment velocity, and LWP (Fig. 13).

During the night and in the morning, $\bar{L}_{\text {buoy }}^{-, 0,+}$ is characterized, relative to $\bar{L}^{-, 0,+}$, by faster boundary layer growth (Fig. 13b) and stronger entrainment (Fig. 13c). It is hence 
buoyancy-driven dynamics, rather than shear-driven dynamics, that translates faster geostrophic wind into faster boundary layer growth and stronger entrainment during the night and in the morning. This becomes most apparent by considering entrainment velocity $w_{\mathrm{e}}$ (Eq. 5) averaged over period $\mathrm{N}$ (Fig. 13c): in the simulations with buoyancy-driven dynamics $\left(\bar{L}_{\text {buoy }}^{-, 0,+}\right), w_{\mathrm{e}}$ increases from $\bar{L}_{\text {buoy }}^{-}$to $\bar{L}_{\text {buoy }}^{0}$ by $0.40 \mathrm{~mm} \mathrm{~s}^{-1}$ and from $\bar{L}_{\text {buoy }}^{0}$ to $\bar{L}_{\text {buoy }}^{+}$by $0.52 \mathrm{~mm} \mathrm{~s}^{-1}$. Including the effect of shear from geostrophic wind $\left(\bar{L}^{-, 0,+}\right)$ reduces the response of $w_{\mathrm{e}}$ to wind speed: it only increases from $\bar{L}^{-}$to $\bar{L}^{0}$ by $0.35 \mathrm{~mm} \mathrm{~s}^{-1}$ and from $\bar{L}^{0}$ to $\bar{L}^{+}$by $0.42 \mathrm{~mm} \mathrm{~s}^{-1}$. Since the surface sensible heat flux is nearly independent of wind speed during period N (Fig. 12b), enhanced boundary layer growth and entrainment at higher wind speed can be exclusively tied to higher TKE production from latent heat release in cloud updrafts at higher wind speed (Sect. 3.1.2), with overall TKE production from shear due to the geostrophic wind speed acting against it. This analysis does not distinguish between the effects of higher shear production of TKE at higher wind speed at the surface and at the inversion (Fig. 11d), and therefore does not determine whether shear production of TKE at the inversion due to geostrophic wind supports entrainment, as locally generated shear does (Wang et al., 2008, 2012; Katzwinkel et al., 2012; Mellado et al., 2014).

A more complex picture of the role of buoyancy- and shear-driven dynamics emerges in the afternoon (period C). At low and reference wind speed, shear due to geostrophic wind renders the boundary layer more decoupled, but the opposite is the case at high wind speed (Fig. 13a). Concurrently, presence of shear from geostrophic wind enhances LWP in period C at all wind speeds (Fig. 13d). Shear production of TKE due to geostrophic wind therefore modulates decoupling and thereby the transport of moisture between the surface and cloud base in the course of the day.

\subsubsection{Modulation of decoupling by geostrophic wind in the course of the diurnal cycle}

During nighttime and for several hours into daytime, the boundary layer is more decoupled in the simulation $\bar{L}^{-, 0,+}$ compared to the simulations $\bar{L}_{\text {buoy }}^{-, 0,+}$ (Fig. 13a). Since in the simulations $\bar{L}_{\text {buoy }}^{-, 0,+}$, TKE is not produced from shear due to geostrophic wind, the cause of higher nighttime decoupling at higher wind speed is stronger entrainment (Fig. 13c). A role of boundary layer deepening with wind speed (Fig. 13b) can be excluded because nighttime decoupling remains nearly constant at each wind speed (Fig. 13a), despite a progressive deepening of the boundary layer. Consequently, the cause of higher nighttime decoupling at higher wind speed in the simulations $\bar{L}^{-, 0,+}$ is the combined action of stronger entrainment and stronger production of TKE from shear due to geostrophic wind. In the afternoon (pe- (a)

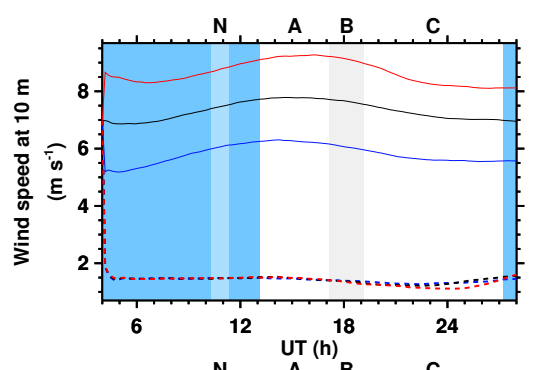

(b)

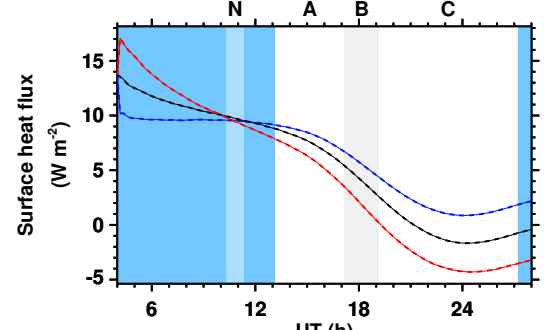

(c)

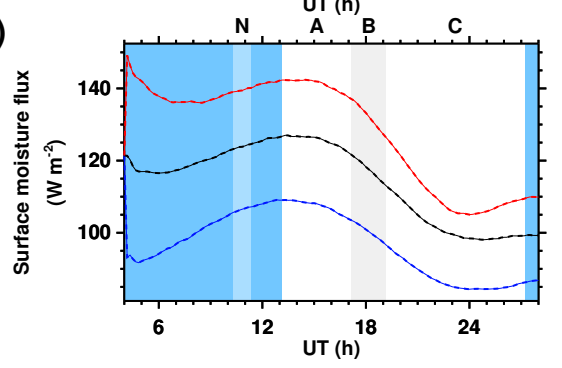

Figure 12. Time series from simulations $\bar{L}^{-}$(blue), $\bar{L}^{0}$ (black), $\bar{L}^{+}$(red), solid curves, and from simulations $\bar{L}_{\text {buoy }}^{-}$(blue), $\bar{L}_{\text {buoy }}^{0}$ (black), $\bar{L}_{\text {buoy }}^{+}$(red), dashed curves.

riod C), however, shear from geostrophic wind acts to maintain higher LWP relative to the simulations without shear (Fig. 13d) and, in the high wind speed case, reduces decoupling (Fig. 13a).

We will identify the mechanism underlying the modulation of boundary layer decoupling by shear-driven dynamics due to geostrophic wind. The decoupling index (Eq. 6) is defined based on the altitude difference between the lifting condensation level and cloud base. The decoupling index is $>0$ when the sub-cloud layer circulation does not efficiently transport moisture from the surface to cloud base. Noting that in the sub-cloud layer, $q_{\mathrm{v}}=q_{\mathrm{t}}$, we shall employ the quantity

$\zeta_{q_{\mathrm{t}}} \doteq-\mathrm{d} \bar{q}_{\mathrm{t}} / \mathrm{d} z$

the negative value of the vertical gradient of the horizontally averaged total water mixing ratio $\overline{q_{\mathrm{t}}}$, to measure the efficiency of vertical moisture transport. $\zeta_{q_{\mathrm{t}}}=0$ indicates perfect mixing, $\zeta_{q_{\mathrm{t}}}>0$ inefficient upward moisture transport by resolved-scale dynamics, subgrid-scale mixing, and physical and numerical diffusion.

Figure 15 shows vertical profiles averaged over the period N (10:20-11:20 UT) from the simulations $\bar{L}^{-, 0,+}$ and 
(a)

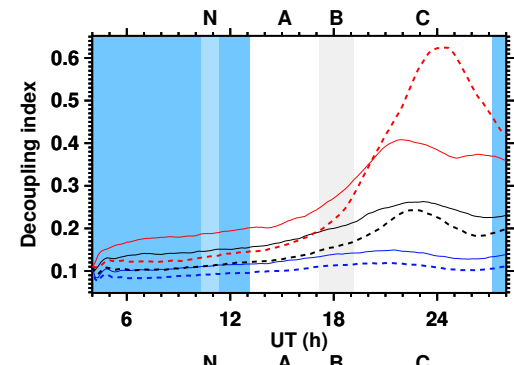

(c)

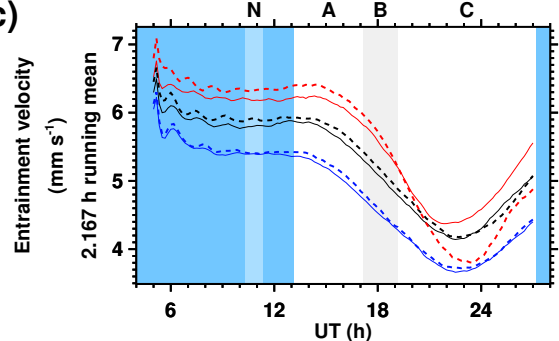

(b)

(d)
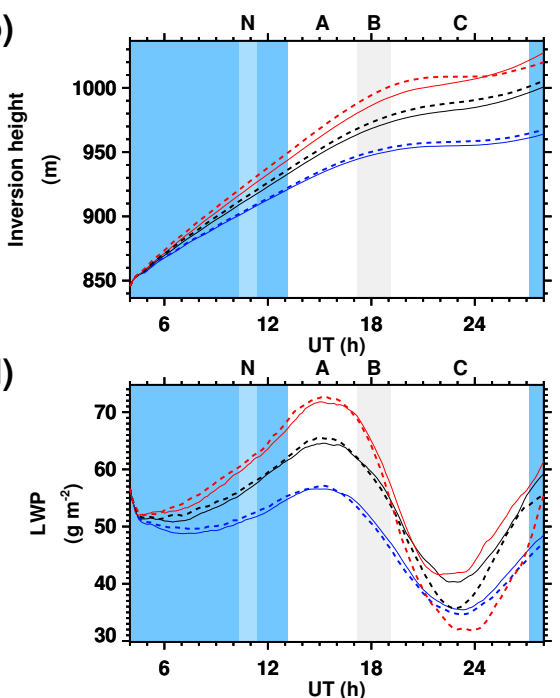

Figure 13. Buoyancy- and shear-driven dynamics. Time series from simulations $\bar{L}^{-}$(blue), $\bar{L}^{0}$ (black), $\bar{L}^{+}$(red), solid curves, and from simulations $\bar{L}_{\text {buoy }}^{-}$(blue), $\bar{L}_{\text {buoy }}^{0}$ (black), $\bar{L}_{\text {buoy }}^{+}$(red), dashed curves. A low-pass (running mean) filter was applied where indicated to reduce noise.

(a)

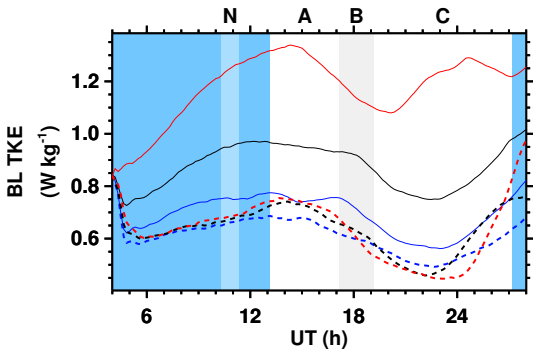

(b)

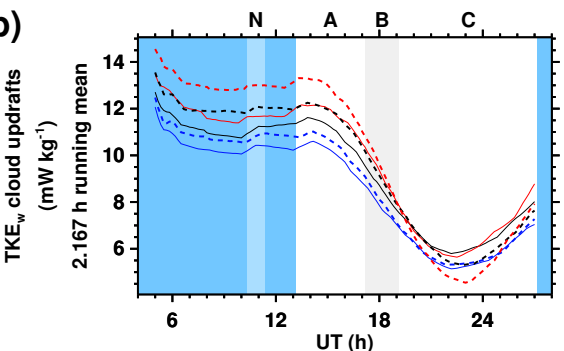

Figure 14. Buoyancy- and shear-driven dynamics. Boundary layer TKE (a) and the vertical TKE component $\left(\mathrm{TKE}_{\mathrm{w}}\right)$ in cloud updrafts (b) are given per total boundary layer air mass. Time series from simulations $\bar{L}^{-}$(blue), $\bar{L}^{0}$ (black), $\bar{L}^{+}$(red), solid curves, and from simulations $\bar{L}_{\text {buoy }}^{-}$(blue), $\bar{L}_{\text {buoy }}^{0}$ (black), $\bar{L}_{\text {buoy }}^{+}$(red), dashed curves. A low-pass (running mean) filter was applied where indicated to reduce noise.

$\bar{L}_{\text {buoy }}^{-, 0,+}$. During this period, shear due to geostrophic wind causes higher decoupling (Fig. 13a). Total water $q_{\mathrm{t}}$ (Fig. 15a) and $\zeta_{q_{\mathrm{t}}}$ (Fig. 15b) show that the efficiency of upward moisture transport in the sub-cloud layer decreases with increasing wind speed or in the presence of shear-driven dynamics due to the geostrophic wind: as wind speed increases or when shear due to geostrophic wind is present, more moisture accumulates near the surface (Fig. 15a), and $\zeta_{q_{\mathrm{t}}}$ assumes larger values (Fig. 15b). The cause of reduced efficiency of vertical moisture transport in the sub-cloud layer is hence shear due to geostrophic wind. Near the surface (in layer $L_{3}$ ), shear from geostrophic wind also suppresses buoyant production of TKE (Fig. 15c).

Figure 16 shows vertical profiles averaged over the afternoon period 22:30-23:30 UT from the simulations $\bar{L}^{-, 0,+}$ and $\bar{L}_{\text {buoy }}^{-, 0,+}$. In this period, shear due to geostrophic wind reduces decoupling at high wind speed (Fig. 13a). This shapes the $q_{\mathrm{t}}$ profiles (Fig. 16a): $q_{\mathrm{t}}$ is higher near the surface in the simulations $\bar{L}^{-, 0}$ than in the simulations $\bar{L}_{\text {buoy }}^{-, 0}$; at high wind speed, however, $q_{\mathrm{t}}$ is lower near the surface in the simulation $\bar{L}^{+}$than in the simulations $\bar{L}_{\text {buoy }}^{+}$. At high wind speed, the $\zeta_{q_{\mathrm{t}}}$ profile (Fig. 16a) shows lower values in the sub-cloud layer in the presence of shear relative to in its absence. Hence at this time of day, at high wind speed, shear caused by geostrophic wind renders vertical moisture transport in the sub-cloud layer more efficient.

Shear due to geostrophic wind has little effect on TKE net production due to buoyancy in the afternoon period 22:3023:30 UT (Fig. 16c) except at high wind speed $\left(\bar{L}^{+}\right.$and $\bar{L}_{\text {buoy }}^{+}$), where it suppresses TKE net production due to buoyancy to values close to 0 in the sub-cloud layer $\left(L_{3}\right)$, while enhancing it at cloud level $\left(L_{2}\right)$. With the very low TKE production due to buoyancy in the sub-cloud layer in the high wind speed conditions, shear due to geostrophic wind becomes the dominant source of TKE at high wind speed between the surface and cloud base (layer $L_{3}$; Fig. 16d). The 
(a)

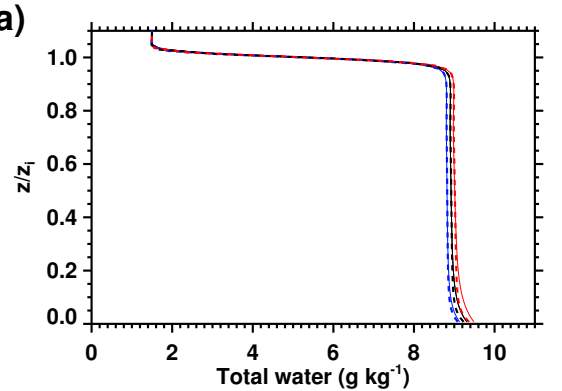

(c)

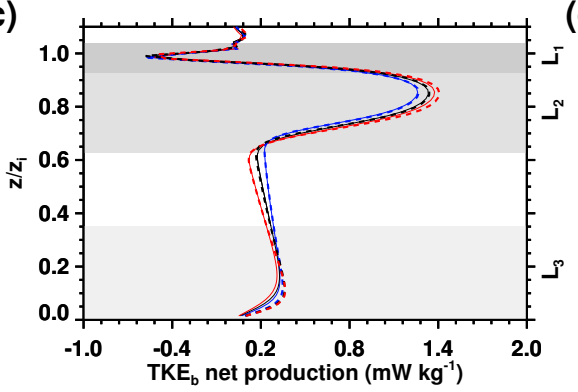

(b)

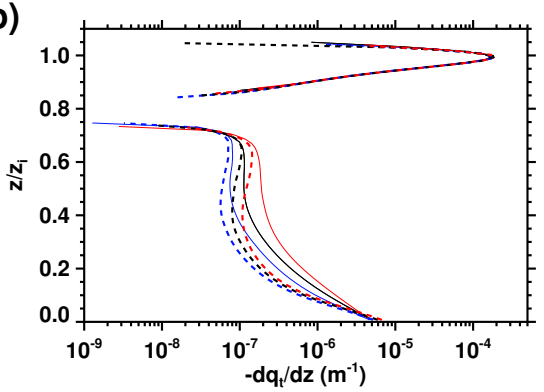

(d)

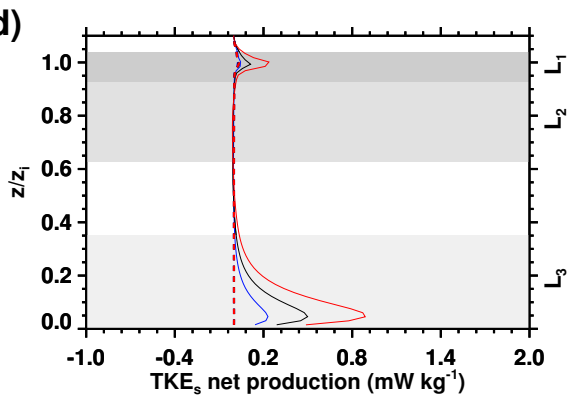

Figure 15. Buoyancy- and shear-driven dynamics. Profiles averaged over the period N (10:20-11:20 UT) from simulations $L^{-}$(blue), $L^{0}$ (black), $L^{+}$(red), solid curves, and from simulations $L_{\text {buoy }}^{-}$(blue), $L_{\text {buoy }}^{0}$ (black), $L_{\text {buoy }}^{+}$(red), dashed curves. TKE $\mathrm{b}_{\mathrm{b}}$ denotes buoyant production, $\mathrm{TKE}_{\mathrm{S}}$ shear production of turbulence kinetic energy.

(a)

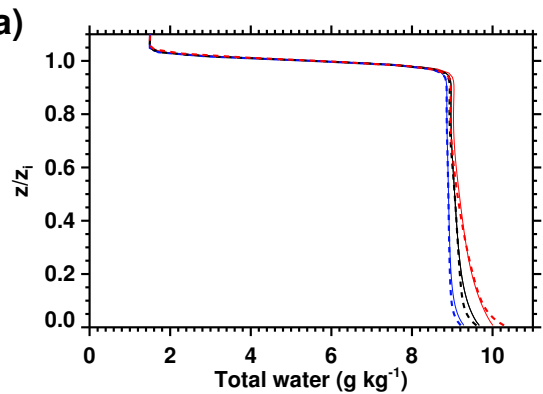

(c)

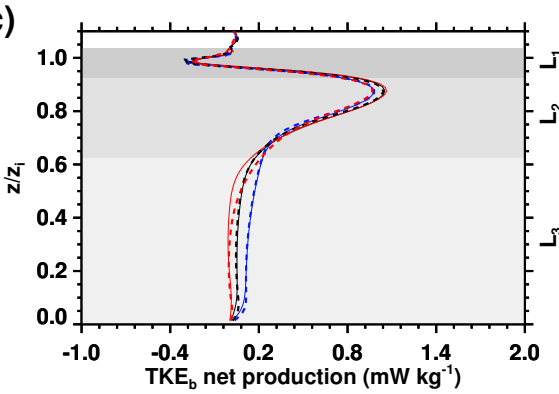

(b)

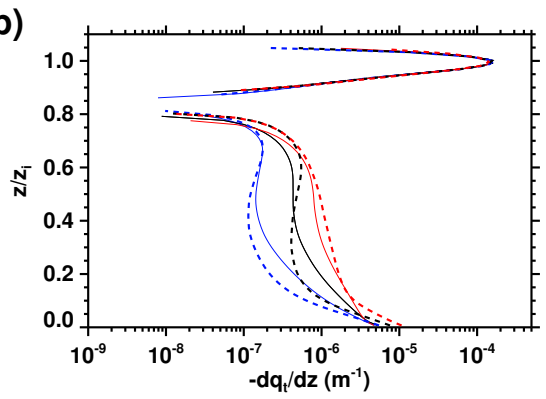

(d)

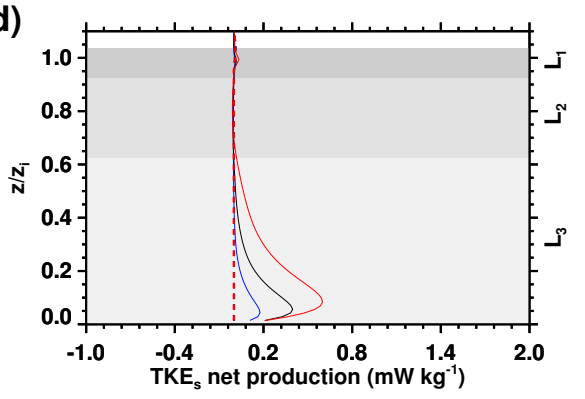

Figure 16. Buoyancy- and shear-driven dynamics. Profiles averaged over $1 \mathrm{~h}$ in the afternoon (22:30-23:30 UT) from simulations $L^{-}$(blue), $L^{0}$ (black), $L^{+}$(red), solid curves, and from simulations $L_{\text {buoy }}^{-}$(blue), $L_{\text {buoy }}^{0}$ (black), $L_{\text {buoy }}^{+}$(red), dashed curves. TKE $\mathrm{b}_{\mathrm{b}}$ denotes buoyant production, $\mathrm{TKE}_{\mathrm{S}}$ shear production of turbulence kinetic energy.

conclusion is that with increasing wind speed at strong decoupling (period C in Fig. 13a), the shear-driven circulation due to geostrophic wind takes over from buoyancy-driven circulation in maintaining vertical moisture transport in the sub-cloud layer. By securing moisture transport between the surface and cloud base, it helps maintain LWP and supports buoyant TKE production at cloud level: in cloud updrafts (layer $L_{2}$ ), the highest TKE net production by buoyancy is present in the high wind speed simulation $\bar{L}^{+}$(Fig. 16c). 


\subsubsection{Cloud layer updrafts as dynamical drivers of entrainment}

A corollary of the comparison between the simulations without $\left(\bar{L}_{\text {buoy }}^{-, 0,+}\right)$ and with $\left(\bar{L}^{-, 0,+}\right)$ shear due to geostrophic wind is that boundary layer growth and entrainment are not tied to total boundary layer TKE: over much of the diurnal cycle, dynamics in the simulations $\bar{L}_{\text {buoy }}^{-, 0,+}$ supports faster boundary layer growth and higher entrainment (Fig. 13b and c), although boundary layer TKE is lower relative to the simulations $\bar{L}^{-, 0,+}$ (Fig. 14a). The additional boundary layer TKE in the simulations $\bar{L}^{-, 0,+}$, relative to the simulations $\bar{L}_{\text {buoy }}^{-, 0,+}$, originates from shear production due to the geostrophic wind. Hence features of boundary layer dynamics that are not represented by total boundary layer TKE constitute the key driver of entrainment. Figure $14 \mathrm{~b}$ shows the time series of the TKE vertical component

$\mathrm{TKE}_{\mathrm{w}}=\frac{w^{\prime 2}}{2}$

in updrafts of the cloud layer. Comparison of $\mathrm{TKE}_{\mathrm{w}}$ (Fig. 14b) and of entrainment velocity $w_{\mathrm{e}}$ (Fig. 13c) shows that these two quantities behave in unison in the course of the diurnal cycle, in response to wind speed, and in response to the presence of shear due to geostrophic wind: in nighttime conditions, and for several hours into daytime, both $\mathrm{TKE}_{\mathrm{W}}$ and $w_{\mathrm{e}}$ increase with wind speed but are suppressed by the action of shear due to geostrophic wind. Both quantities experience a suppression during daytime (period C). During period $\mathrm{C}$ at high wind speed, shear due to geostrophic wind increases both $\mathrm{TKE}_{\mathrm{w}}$ and $w_{\mathrm{e}}$, in contrast to its suppressing effect in nighttime conditions.

In Sect. 3.1.2, we found that wind speed drives boundary layer growth and entrainment by boosting buoyant production of TKE from latent heat release in cloud updrafts. This, together with the concomitant behavior of cloud updraft $\mathrm{TKE}_{\mathrm{w}}$ and $w_{\mathrm{e}}$ in the course of the diurnal cycle, in response to wind speed, and to the presence/absence of shear due to geostrophic wind suggests that cloud layer updrafts are a key dynamical driver of boundary layer growth and entrainment in stratocumulus clouds. However, because the evolution and behavior of cloud updraft $w_{\mathrm{e}}$ and $\mathrm{TKE}_{\mathrm{w}}$ are not identical (Figs. 13c and 14b), additional factors determining the entrainment velocity $w_{\mathrm{e}}$ likely exist.

\section{Conclusions}

Observations have identified global and regional trends towards faster surface wind speed over the oceans in the 20th century (Young et al., 2011; Hande et al., 2012; Bertin et al., 2013; Servain et al., 2014). These trends are not necessarily a consequence of climate change but could arise from internal climate variability (Dobrynin et al., 2015). Concurrently, climate simulations predict changes in ocean wind speeds in the course of the 21st century (McInnes et al., 2011; Hemer et al., 2013). Wind speed drives the surface fluxes of sensible heat, moisture, and momentum and thereby impacts cloud liquid water path and cloud radiative properties. Long-term changes in large-scale wind speed and the associated cloud response therefore constitute a cloud-climate feedback mechanism, with the potential to impact Earth's radiation budget, the formation of precipitation, and the effect of aerosol on clouds.

We have investigated the response of non-precipitating, overcast marine stratocumulus clouds to changes in largescale wind speed, all else equal, over the course of a diurnal cycle. The goal of the investigation was to identify and explain the dynamical processes by which wind speed acts on the evolution of boundary layer growth, entrainment, decoupling, LWP, and CRE. Furthermore, we explored the role of buoyancy- and shear-driven dynamics for boundary layer growth, entrainment, decoupling, and LWP at different wind speeds. We focused on the dynamical rather than the microphysical response of the stratocumulus-topped boundary layer to changes in wind speed, and we excluded the effect of wind speed on surface aerosol production and loss.

We used cloud-system resolving simulations which were initialized with boundary layer properties, cloud properties, and dynamics from observations. Owing to identical initial and boundary conditions, the simulations are suited to identify and characterize the mechanisms by which the stratocumulus-topped marine boundary layer responds on the timescale of a diurnal cycle to different wind speeds. However, they do not represent a stratocumulus-topped marine boundary layer in a future climate at different wind speeds, which would require initial and boundary conditions that are consistent with the chosen climate and wind speeds. The results and their analysis are therefore specific for the cloud state and the initial and boundary conditions considered.

We find that higher wind speed leads to faster boundary layer growth and entrainment. The dynamical driver is enhanced buoyant production of TKE from latent heat release in cloud updrafts. Concomitant behavior of the cloud updraft vertical component of TKE and of entrainment velocity in the course of the diurnal cycle, in response to wind speed, and in response to the presence or absence of shear due to geostrophic wind suggests that cloud updrafts are a key dynamical driver of boundary layer growth and entrainment in stratocumulus clouds. However, additional factors determining entrainment likely exist.

Higher wind speed enhances LWP during the night and in the morning and more strongly suppresses it later in the day. Wind speed hence accentuates the diurnal LWP cycle by expanding the morning-afternoon contrast. The higher LWP at higher wind speed does not, however, enhance cloud top cooling because in clouds with LWP $\approx 50 \mathrm{~g} \mathrm{~m}^{-2}$, longwave emissions are insensitive to LWP. This leads to the general conclusion that in sufficiently thick stratocumulus clouds, additional boundary layer growth and entrainment due to a 
boundary layer moistening arises by stronger production of TKE from latent heat release in cloud updrafts rather than from enhanced longwave cooling.

We find that large-scale wind modulates boundary layer decoupling. At nighttime and at low wind speed during daytime, it enhances decoupling in part by faster boundary layer growth and stronger entrainment, and in part because circulation driven by shear from large-scale wind in the sub-cloud layer hinders vertical moisture transport between the surface and cloud base. With increasing wind speed, however, in decoupled daytime conditions, shear-driven circulation due to large-scale wind takes over from buoyancy-driven circulation in transporting moisture from the surface to cloud base and thereby reduces decoupling and helps maintain LWP.

The total (shortwave + longwave) CRE is sensitive to wind speed in our diurnal cycle simulations: the enhancement of LWP by wind speed during the night and in the morning results in a stronger diurnally averaged CRE. The CRE response to wind speed depends on the time of the day. It is strongest shortly before noon, when CRE peaks, and becomes weaker later in the day owing to the wind speedenhanced daytime suppression of LWP. The compensation between nighttime/morning LWP enhancement and suppression later in the day makes the diurnally averaged CRE less sensitive to wind speed as wind speed increases.
On longer (climatic) timescales, wind speed may act differently on the CRE than in the course of one diurnal cycle. We hypothesize that on longer time scales, a higher wind speed would also render the nighttime, non-precipitating, stratocumulus-topped boundary layer more decoupled and less decoupled at lower wind speed. During daytime, the effect of wind speed on decoupling on longer timescales will depend on whether production of turbulence in the sub-cloud layer by shear from large-scale wind supports or suppresses vertical moisture transport from the surface to cloud base. The response may depend on local conditions. Key questions are how future changes in large-scale wind speed will modify cloud properties and the CRE on longer timescales, and how their effect compares to the effect of changes in sea surface temperature, atmospheric moisture, $\mathrm{CO}_{2}$ content, subsidence strength, and inversion stability. 


\section{Appendix A: Nudging}

We used Newtonian relaxation (e.g., Jeuken et al., 1996) of select prognostic variables to generate conditions (temperature, water content, dynamics, cloud properties) in the final state of spin-up runs that are consistent with DYCOMSII RF01 observations (Stevens et al., 2005). The final state of spin-up runs initializes the simulations. This has the advantage (relative to an initialization with a static initial state with a prescribed total water content, present as water vapor, and with a 0 cloud water content) that the simulations are not biased by the model working to establish dynamics and a cloud deck from a static state. In the simulations, we used nudging to ensure that free-tropospheric potential temperature and water vapor do not drift due to subsidence, which would, among other things, increase the potential temperature jump across the inversion and affect the boundary layer underneath.

We distinguish soft and hard nudging. In soft nudging, the nudging term of a quantity $X$ is

$$
\frac{\Delta_{\text {nudging }} X(x, y, z, t)}{\Delta t}=-\frac{\bar{X}(z, t)-X_{\text {target }}(z)}{\tau_{X}} .
$$

It is calculated from the deviation of the horizontal mean $\bar{X}(z, t)$ from the target vertical profile $X_{\text {target }}(z) . \tau_{X}$ is the nudging time constant, $\Delta t$ the model time step. In hard nudging, the nudging term is calculated from the local deviation $X(x, y, z, t)$ from the target vertical profile $X_{\text {target }}(z)$ :

$$
\frac{\Delta_{\text {nudging }} X(x, y, z, t)}{\Delta t}=-\frac{X(x, y, z, t)-X_{\text {target }}(z)}{\tau_{X}} .
$$

In either soft or hard nudging the nudging term is passed as a tendency of $X$ to the dynamical core of the model.

The distinction between soft and hard nudging can be motivated by considering potential temperature: under soft nudging, the surface sensible heat flux, dynamics, cloud processes, and radiative heating/cooling are permitted to modify potential temperature locally under the constraint that the domain mean profile is maintained at its target value. In hard nudging, the action of these processes would be suppressed and potential temperature would maintain the target profile locally. The choice between soft and hard nudging will depend on the preferred target state.

\section{A1 Spin-up runs}

Potential temperature $\theta(x, y, z, t)$ was soft-nudged at each location $(x, y, z)$ in the boundary layer and free troposphere in proportion to the deviation of the horizontal $(z)$ mean liquid water potential temperature $\bar{\theta}_{1}(z, t)$ from the initial liquid water potential temperature $\theta_{\mathrm{l}}(z, t=0)$ :

$$
\frac{\Delta_{\text {nudging }} \theta(x, y, z, t)}{\Delta t}=-\frac{\bar{\theta}_{1}(z, t)-\theta_{1}(z, t=0)}{\tau_{\theta}} .
$$

We calculated the nudging term of $\theta$ from $\theta_{1}$ because $\theta_{1}(z$, $t=0)=\theta(z, t=0)$ and because $\theta_{1}$ is conserved under water phase changes. In other words, $\theta$ is nudged to maintain $\bar{\theta}_{1}(z$, $t)$ at its initial value $\theta_{1}(z, t=0)$. We applied hard nudging to water vapor $\left(q_{\mathrm{v}}\right)$ in the free troposphere $(10 \mathrm{~m}$ higher than the inversion):

$\frac{\Delta_{\text {nudging }} q_{\mathrm{v}}(x, y, z, t)}{\Delta t}=-\frac{q_{\mathrm{v}}(x, y, z, t)-q_{\mathrm{t}}(z, t=0)}{\tau_{q_{\mathrm{v}}}}$.

In the boundary layer, the water variables (water vapor $q_{\mathrm{v}}$, cloud water $q_{\mathrm{c}}$, rain water $q_{\mathrm{r}}$, and total water $q_{\mathrm{t}}=q_{\mathrm{v}}+q_{\mathrm{c}}+q_{\mathrm{r}}$ ) were not nudged in order allow the nudged mean potential temperature profile, the surface sensible heat fluxes, dynamics, radiative heating/cooling, and cloud microphysics determine their evolution.

Hard nudging was applied in the following manner to the interstitial aerosol number $\widetilde{N}_{\mathrm{m}}$ and mass $\widetilde{M}_{\mathrm{m}, n}$, both in the boundary layer and the free troposphere:

$$
\begin{aligned}
& \frac{\Delta_{\text {nudging }} \widetilde{N}_{\mathrm{m}}(x, y, z, t)}{\Delta t}=-\frac{N_{\mathrm{m}}(x, y, z, t)-N_{\mathrm{m}}(t=0)}{\tau_{\text {aerosol }}} \\
& \frac{\Delta_{\text {nudging }} \widetilde{M}_{\mathrm{m}, n}(x, y, z, t)}{\Delta t}=-\frac{M_{\mathrm{m}, n}(x, y, z, t)-M_{\mathrm{m}, n}(t=0)}{\tau_{\text {aerosol }}} .
\end{aligned}
$$

The index " $m$ " denotes the three log-normal aerosol modes (Aitken, accumulation, and coarse), the index " $n$ " the chemical species. $N_{\mathrm{m}}$ and $M_{\mathrm{m}, n}$ are the total aerosol number and mass, $N_{\mathrm{m}}(t=0)$ and $M_{\mathrm{m}, n}(t=0)$ their initial (and nudging target) values, respectively. Although the nudging term is calculated from the total aerosol number and mass, it is applied to interstitial aerosol only to allow cloud microphysics determine the aerosol number and mass residing inside cloud and rain drops. In the spin-up runs, the Aitken and coarse modes were held at 0 number and mass. The accumulation mode number was nudged towards $300 \mathrm{mg}^{-1}$, containing $4.74 \mu \mathrm{g} \mathrm{kg}^{-1}$ of sulfate, with a dry geometric mean (median) diameter of $200 \mu \mathrm{m}$ and a geometric standard deviation of 1.5. We used the time constants $\tau_{\theta}=\tau_{q_{\mathrm{v}}}=\tau_{\text {aerosol }}=300 \mathrm{~s}$.

\section{A2 Simulations}

We applied soft nudging to potential temperature and water vapor in the free troposphere of the simulations:

$$
\begin{aligned}
& \frac{\Delta_{\text {nudging }} \theta(x, y, z, t)}{\Delta t}=-\frac{\bar{\theta}(z, t)-\theta(z, t=0)}{\tau_{\theta}} \\
& \frac{\Delta_{\text {nudging }} q_{\mathrm{v}}(x, y, z, t)}{\Delta t}=-\frac{\bar{q}_{\mathrm{v}}(z, t)-q_{\mathrm{t}}(z, t=0)}{\tau_{q_{\mathrm{v}}}} .
\end{aligned}
$$

In this soft nudging, potential temperature and water vapor are nudged only to the extent that their horizontal mean values deviate from the initial profiles and are otherwise allowed to vary in response to dynamics and radiative heating/cooling. Still, as a precaution, the nudging is applied only $50 \mathrm{~m}$ or higher above the inversion, so as to not to interfere 
with processes at the inversion. No nudging is performed in the boundary layer and below $50 \mathrm{~m}$ above the inversion. The nudging scheme accommodates changes in inversion height: the altitude above which nudging is applied moves up and down with the inversion. Should the inversion descend below its initial height, potential temperature and water vapor are nudged towards linear extrapolations of their initial freetropospheric profiles. This does not occur in the simulations in this work. We used the time constants $\tau_{\theta}=\tau_{q_{\mathrm{v}}}=300 \mathrm{~s}$. In contrast to the spin-up runs, aerosol number and mass are not nudged in the simulations.

\section{Appendix B: Boundary layer water budget}

The boundary layer water budget equation is derived. ( $x$, $y, z)$ form a right-handed Cartesian coordinate system with $z$ pointing up; $t$ is the time. The boundary layer mean water mass path (vertically integrated water mass per horizontal area) is

$$
Q(t)=\frac{1}{A} \iint_{A} \mathrm{~d} x \mathrm{~d} y \int_{0}^{z_{\mathrm{i}}(x, y, t)} \mathrm{d} z \rho(x, y, z, t),
$$

where $\rho$ is the volumetric mass density of water, $A$ is the horizontal area covered by the simulation domain, and $z_{\mathrm{i}}$ is the inversion height. The Leibniz integral rule gives

$$
\begin{aligned}
\frac{\mathrm{d} Q(t)}{\mathrm{d} t} & =\frac{1}{A} \iint_{A} \mathrm{~d} x \mathrm{~d} y \int_{0}^{z_{\mathrm{i}}(x, y, t)} \mathrm{d} z \frac{\partial \rho(x, y, z, t)}{\partial t} \\
& +\frac{1}{A} \iint_{A} \mathrm{~d} x \mathrm{~d} y \rho\left(x, y, z_{\mathrm{i}}, t\right) \frac{\partial z_{\mathrm{i}}(x, y, t)}{\partial t} .
\end{aligned}
$$

With the mass continuity equation

$\frac{\partial \rho}{\partial t}=-\nabla(\boldsymbol{v} \rho)$,

one obtains

$$
\begin{aligned}
\frac{\mathrm{d} Q(t)}{\mathrm{d} t} & =-\frac{1}{A} \iint_{A} \mathrm{~d} x \mathrm{~d} y \int_{0}^{z_{\mathrm{i}}(x, y, t)} \mathrm{d} z \nabla(\boldsymbol{v} \rho) \\
& +\frac{1}{A} \iint_{A} \mathrm{~d} x \mathrm{~d} y \rho\left(x, y, z_{\mathrm{i}}, t\right) \frac{\partial z_{\mathrm{i}}(x, y, t)}{\partial t},
\end{aligned}
$$

where $v$ is water transport velocity. Applying the divergence theorem yields

$$
\begin{aligned}
\frac{\mathrm{d} Q(t)}{\mathrm{d} t}= & -\frac{1}{A} \oiint_{S} \mathrm{~d} \boldsymbol{s} v \rho+\frac{1}{A} \iint_{A} \mathrm{~d} x \mathrm{~d} y \rho\left(x, y, z_{\mathrm{i}}, t\right) \\
& \frac{\partial z_{\mathrm{i}}(x, y, t)}{\partial t},
\end{aligned}
$$

where $S$ is the closed surface enveloping the boundary layer and $\mathrm{d} s$ an outward pointing surface element. On the right- hand side of Eq. (B5), the first term represents water transport across $S$, and the second term changes in boundary layer total water due to changes in the location and shape of the inversion. In a horizontally periodic simulation domain the first term reduces to the water flux at the boundary layer base $\left(F_{\text {base }}^{q}\right)$ and at the inversion $\left(F_{\text {inv }}^{q}\right)$ :

$-\frac{1}{A} \oiint_{S} \mathrm{~d} \boldsymbol{s} \boldsymbol{v} \rho=F_{\text {base }}^{q}-F_{\text {inv }}^{q}$.

We will show that the second term on the right-hand side of Eq. (B5) decomposes into a part associated with the temporal change in mean inversion height $\bar{z}_{\mathrm{i}}$ and into a part associated with local fluctuations of the inversion height $\Delta z_{\mathrm{i}}$. We define

$z_{\mathrm{i}}(x, y, t) \doteq \bar{z}_{\mathrm{i}}(t)+\Delta z_{\mathrm{i}}(x, y, t)$,

where $\bar{z}_{\mathrm{i}}(t)$ is the mean inversion height, with the local inversion height deviations having a 0 mean:

$\frac{1}{A} \iint_{A} \mathrm{~d} x \mathrm{~d} y \Delta z_{\mathrm{i}}(x, y, t)=0$.

This gives

$\frac{\partial z_{\mathrm{i}}(x, y, t)}{\partial t}=\frac{\mathrm{d} \bar{z}_{\mathrm{i}}(t)}{\mathrm{d} t}+\frac{\partial \Delta z_{\mathrm{i}}(x, y, t)}{\partial t}$.

Similarly, we define

$\rho\left(x, y, z_{\mathrm{i}}, t\right) \doteq \bar{\rho}_{\mathrm{i}}(t)+\Delta \rho_{\mathrm{i}}(x, y, t)$,

where $\bar{\rho}_{\mathrm{i}}(t)$ is the mean volumetric mass density of water at the inversion, with the local deviations along the inversion having a 0 mean:

$\frac{1}{A} \iint_{A} \mathrm{~d} x \mathrm{~d} y \Delta \rho_{\mathrm{i}}(x, y, t)=0$.

It is then straightforward to show that

$$
\begin{aligned}
& \frac{1}{A} \iint_{A} \mathrm{~d} x \mathrm{~d} y \rho\left(x, y, z_{\mathrm{i}}, t\right) \frac{\partial z_{\mathrm{i}}(x, y, t)}{\partial t}=\bar{\rho}_{\mathrm{i}}(t) \\
& \frac{\mathrm{d} \bar{z}_{\mathrm{i}}(t)}{\mathrm{d} t}+\frac{1}{A} \iint_{A} \mathrm{~d} x \mathrm{~d} y \Delta \rho_{\mathrm{i}}(x, y, t) \frac{\partial \Delta z_{\mathrm{i}}(x, y, t)}{\partial t} .
\end{aligned}
$$

The entrainment flux of water

$F_{\text {entrainment }}^{q} \doteq-\bar{\rho}_{\mathrm{i}}(t) \frac{\mathrm{d} \overline{\mathrm{z}}_{\mathrm{i}}(t)}{\mathrm{d} t}$

is associated with changes in mean inversion height. The term

$$
F_{\text {fluctuations }}^{q} \doteq-\frac{1}{A} \iint_{A} \mathrm{~d} x \mathrm{~d} y \Delta \rho_{\mathrm{i}}(x, y, t) \frac{\partial \Delta z_{\mathrm{i}}(x, y, t)}{\partial t}
$$


is associated with fluctuations of the inversion height about its mean. The sign in the definition of $F_{\text {entrainment }}^{q}$ and $F_{\text {fluctuations }}^{q}$ is a matter of convention. Note that a temporally constant mean inversion height forces $F_{\text {entrainment }}^{q}=0$ but not necessarily $F_{\text {fluctuations }}^{q}=0$. Overall we can write

$\frac{\mathrm{d} Q(t)}{\mathrm{d} t}=F_{\text {base }}^{q}-F_{\text {inv }}^{q}-F_{\text {entrainment }}^{q}-F_{\text {fluctuations }}^{q}$.

It remains to specify the meaning of $F_{\text {base }}^{q}$ and $F_{\text {inv }}^{q}$. These are unrelated to changes in the location and shape of the inversion, which are represented by $F_{\text {entrainment }}^{q}$ and $F_{\text {fluctuations }}^{q}$. We hence account for surface precipitation $\left(F_{\text {precipitation }}^{q}\right)$ and the surface moisture flux $\left(F_{\text {surface }}^{q}\right)$, and for subsidence $\left(F_{\text {subsidence }}^{q}\right)$, resolved-scale dynamics $\left(F_{\text {resolved }}^{q}\right)$, sub-gridscale dynamics $\left(F_{\text {unresolved }}^{q}\right)$, and spurious mixing $\left(F_{\text {spurious }}^{q}\right)$ at the inversion:

$F_{\text {base }}^{q} \doteq F_{\text {precipitation }}^{q}+F_{\text {surface }}^{q}$

$F_{\text {inv }}^{q} \doteq F_{\text {subsidence }}^{q}+F_{\text {resolved }}^{q}+F_{\text {unresolved }}^{q}+F_{\text {spurious }}^{q}$.

The boundary layer water budget equation then reads

$$
\begin{aligned}
\frac{\mathrm{d} Q(t)}{\mathrm{d} t} & =F_{\text {precipitation }}^{q}+F_{\text {surface }}^{q}-F_{\text {entrainment }}^{q} \\
& -F_{\text {subsidence }}^{q}-F_{\text {fluctuations }}^{q}-F_{\text {resolved }}^{q} \\
& -F_{\text {unresolved }}^{q}-F_{\text {spurious }}^{q} .
\end{aligned}
$$

We define $F_{\text {mixing }}^{q}$, the water flux across the inversion due resolved-scale and sub-grid-scale dynamics at the inversion, fluctuations in inversion height, and spurious mixing:

$$
\begin{aligned}
F_{\text {mixing }}^{q} & =F_{\text {fluctuations }}^{q}+F_{\text {resolved }}^{q}+F_{\text {unresolved }}^{q} \\
& +F_{\text {spurious }}^{q} .
\end{aligned}
$$

The boundary layer water budget equation then reads

$$
\begin{aligned}
\frac{\mathrm{d} Q(t)}{\mathrm{d} t} & =F_{\text {precipitation }}^{q}+F_{\text {surface }}^{q}-F_{\text {entrainment }}^{q} \\
& -F_{\text {subsidence }}^{q}-F_{\text {mixing }}^{q} .
\end{aligned}
$$

\section{Appendix C: Resolution}

The dependence on resolution of boundary layer growth, entrainment, decoupling, LWP, and CRE in the course of a diurnal cycle at different wind speeds is documented here. The simulations $M_{\text {fine }}^{-, 0,+}$ with double resolution in each dimension are compared with the simulations $M^{-, 0,+}$ (Table 2). Figures $\mathrm{C} 1-\mathrm{C} 4$ (time series) and $\mathrm{C} 5-\mathrm{C} 10$ (vertical profiles) illustrate the comparison.

The high-resolution simulations have systematically higher LWP values than the reference resolution simulations (Fig. C1a). This is a consequence of reduced mixing at the inversion at higher resolution (Sect. 2.1.2); the finding is supported by the cloud water profiles (Figs. C5a, b and C8a, b): lower resolution leads to a stronger reduction of cloud water in downdrafts compared to updrafts. The LWP response to wind speed and the evolution of LWP in the course of the diurnal cycle are robust against an increase in resolution. In particular, higher wind speed causes higher LWP values in the morning and a stronger LWP suppression later in the day at both resolutions, thereby expanding the morningafternoon contrast and accentuating the LWP diurnal cycle (Sect. 3.1.3).

The high-resolution simulations have a higher cloud fraction (Fig. C1b) due to reduced mixing and entrainment at the inversion at higher resolution. Owing to the systematically higher LWP values and higher cloud fraction, the highresolution simulations have a stronger CRE (Fig. C1c). The CRE peaks shortly before noon at both resolutions with values that increase with wind speed, while afternoon CRE values become less dependent on wind speed owing to the wind speed-dependent daytime suppression of LWP (Sect. 3.1.3).

Boundary layer height (Fig. C1d) and entrainment rate (Fig. C2a) depend weakly on resolution, indicating that the model is robust in this respect against higher mixing and entrainment at the lower resolution. The higher-resolution simulations produce, however, systematically higher decoupling (Fig. C2b). This higher decoupling has little effect on surface $(10 \mathrm{~m})$ wind speed (Fig. C2c) but increases surface layer temperature (Fig. C2d) and water vapor (Fig. C3a). Despite the higher surface layer temperature and moisture, the parameterizations of the surface sensible heat and moisture fluxes produce similar surface fluxes at the two resolutions (Fig. C3b and c).

Vertical total water profiles are shown in Figs. C5c and C8c. Reduced mixing and entrainment at the inversion increases total water content throughout the boundary layer, while higher decoupling at higher resolution increases total water near the surface (see also Fig. C3a). Profiles of $\zeta_{q_{t}}$ (Figs. C5d and C8d) reveal that at higher resolution, vertical moisture transport becomes less efficient only near the surface $\left(z / z_{\mathrm{i}}=0\right.$ to $\left.z / z_{\mathrm{i}} \approx 0.1\right)$. Concurrently, resolved-scale vertical moisture transport is stronger at higher resolution throughout the boundary layer (Figs. C6 and C9). We conclude that the cause of higher decoupling at higher resolution is a reduced efficiency of subgrid-scale vertical transport (not shown), which dominates vertical transport near the surface.

Increased resolution has only a small effect on TKE production by buoyancy in the sub-cloud layer both during the nighttime period N (10:20-11:20 UT) (Fig. C7a) as well as in the afternoon (22:30-23:30 UT) (Fig. C10a). However, TKE production by shear strongly increases with resolution in the sub-cloud layer (Figs. C7b and C10b). Concurrently, TKE production by buoyancy is enhanced at cloud level at higher resolution (Figs. C7a and C10a). Stratification of TKE production by buoyancy by updrafts and downdrafts (Figs. C7c, d and C10c, d) reveals that the additional TKE 
production by buoyancy at cloud level originates from downdrafts. This is a consequence of reduced mixing and entrainment at the inversion at higher resolution, which leads to reduced entrainment warming and drying of cloud-level downdrafts. The effect also appears in the time series of TKE production by buoyancy, stratified by updrafts and downdrafts in the cloud- and sub-cloud layer (Fig. C4): the time series of TKE production by buoyancy in cloud downdrafts (Fig. C4a) shows a systematic increase in response to higher resolution. 
(a)

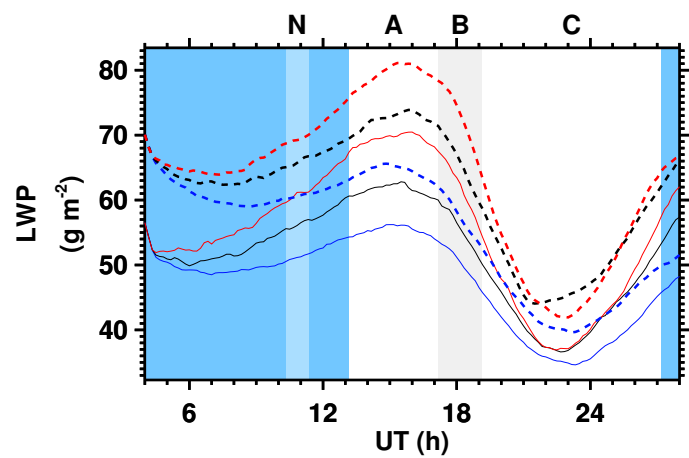

(c)

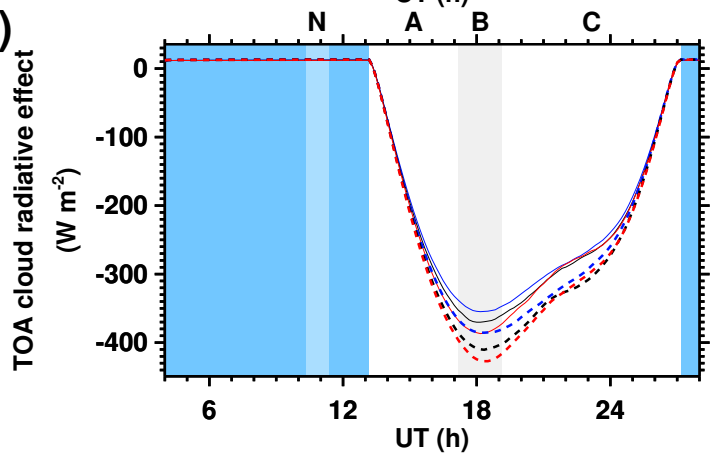

(b)

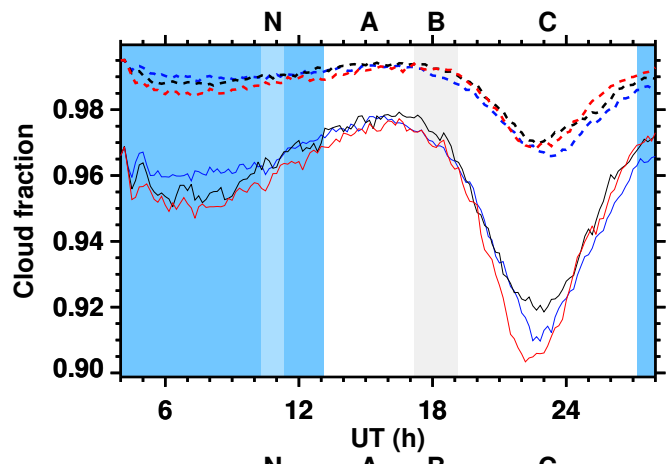

(d)

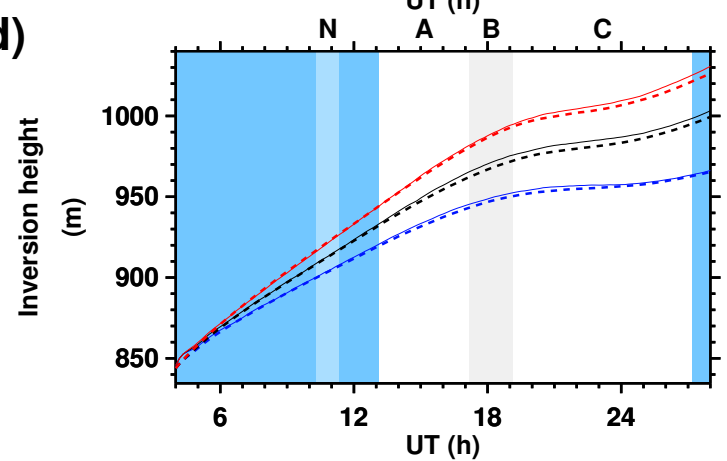

Figure C1. Effect of resolution. Solid curves denote simulations with the base resolution, dashed curves simulations with double resolution in each dimension (Table 2). $M^{-}$(blue solid), $M^{0}$ (black solid), $M^{+}$(red solid); $M_{\text {fine }}^{-}$(blue dashed), $M_{\text {fine }}^{0}$ (black dashed), $M_{\text {fine }}^{+}$(red dashed).

(a)

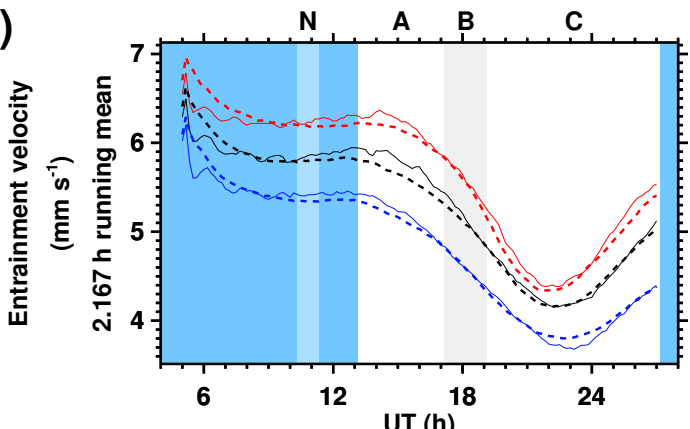

(c)

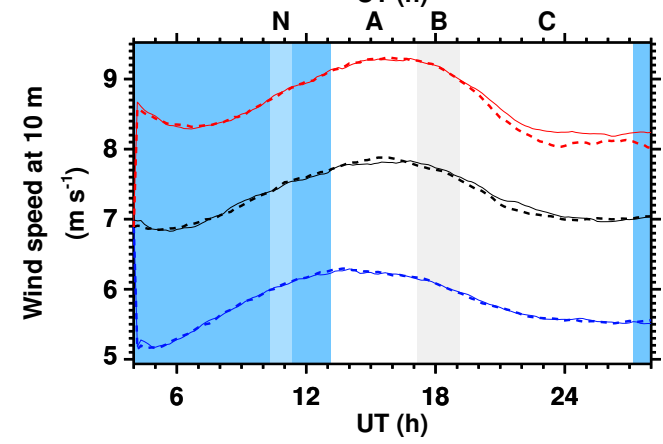

(b)

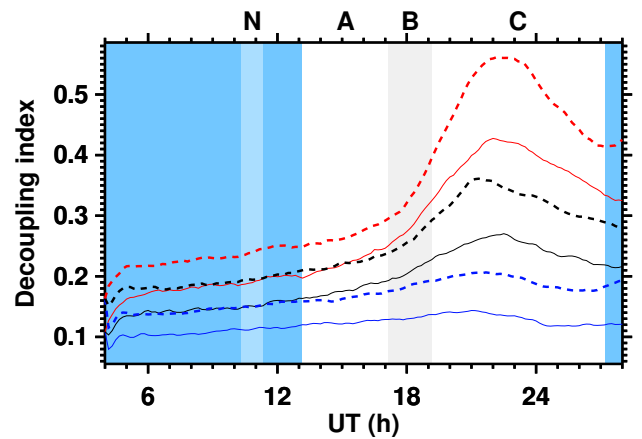

(d)

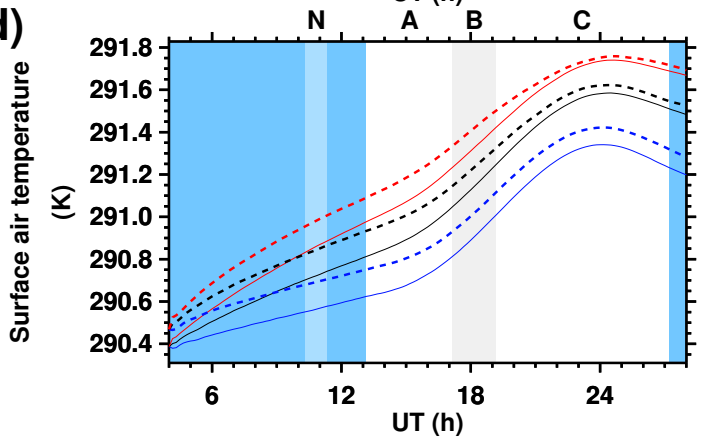

Figure C2. Effect of resolution. Solid curves denote simulations with the base resolution, dashed curves simulations with double resolution in each dimension (Table 2). $M^{-}$(blue solid), $M^{0}$ (black solid), $M^{+}$(red solid); $M_{\text {fine }}^{-}$(blue dashed), $M_{\text {fine }}^{0}$ (black dashed), $M_{\text {fine }}^{+}$(red dashed). A low-pass (running mean) filter was applied where indicated to reduce noise. 
(a)

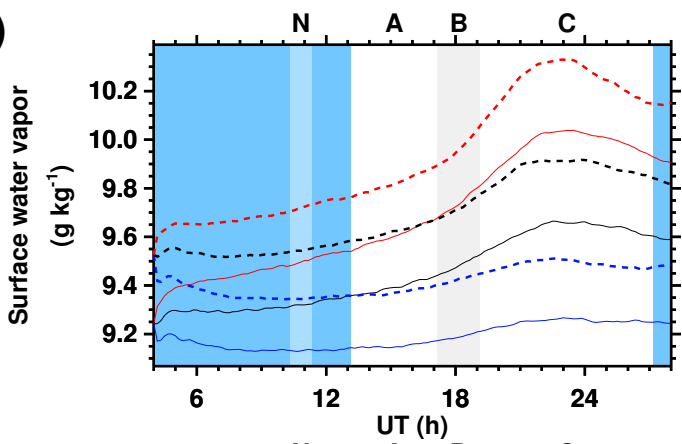

(c)

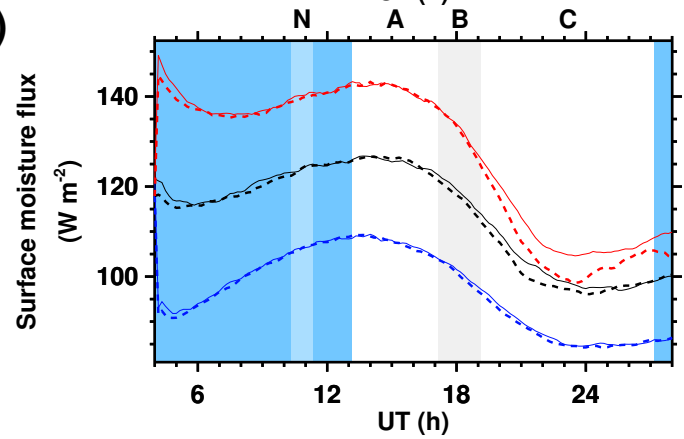

(b)

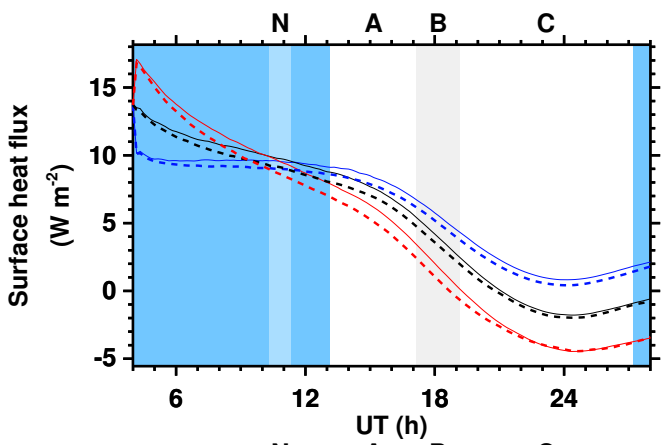

(d)

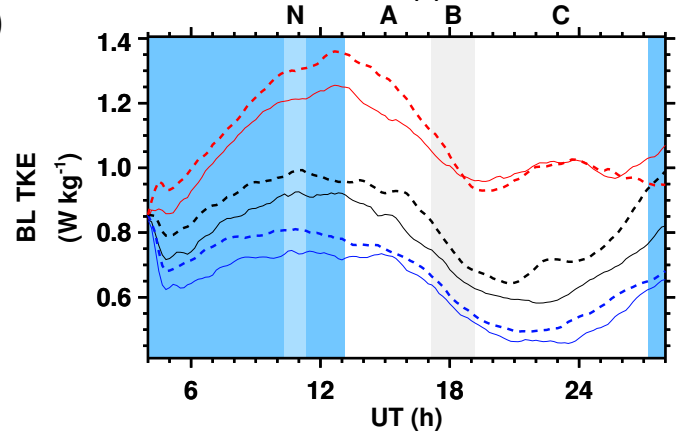

Figure C3. Effect of resolution. Solid curves denote simulations with the base resolution, dashed curves simulations with double resolution in each dimension (Table 2). $M^{-}$(blue solid), $M^{0}$ (black solid), $M^{+}$(red solid); $M_{\text {fine }}^{-}$(blue dashed), $M_{\text {fine }}^{0}$ (black dashed), $M_{\text {fine }}^{+}$(red dashed).
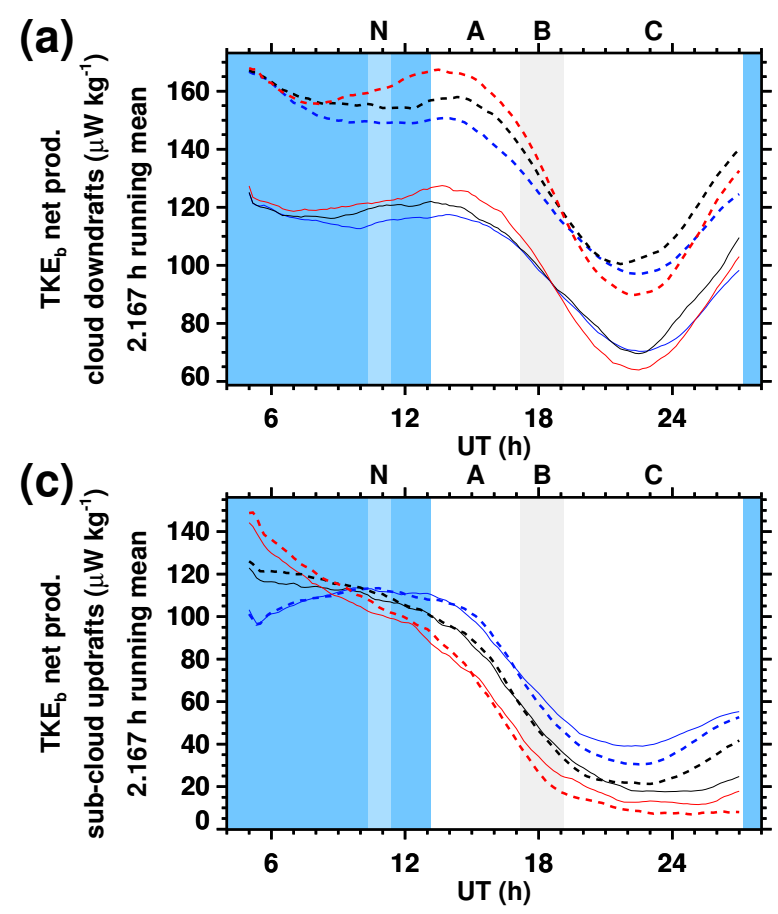
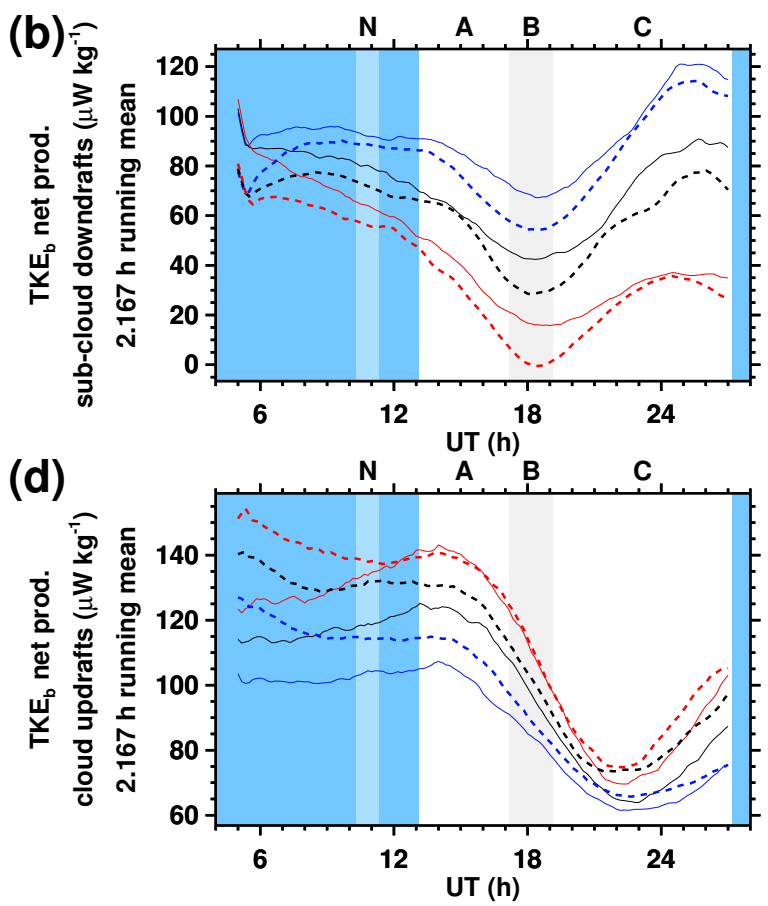

Figure C4. Effect of resolution. Solid curves denote simulations with the base resolution, dashed curves simulations with double resolution in each dimension (Table 2). $M^{-}$(blue solid), $M^{0}$ (black solid), $M^{+}$(red solid); $M_{\text {fine }}^{-}$(blue dashed), $M_{\text {fine }}^{0}$ (black dashed), $M_{\text {fine }}^{+}$(red dashed). $\mathrm{TKE}_{\mathrm{b}}$ denotes buoyant production of turbulence kinetic energy. TKE production rates are given per total boundary layer air mass. A low-pass (running mean) filter was applied where indicated to reduce noise. 
(a)

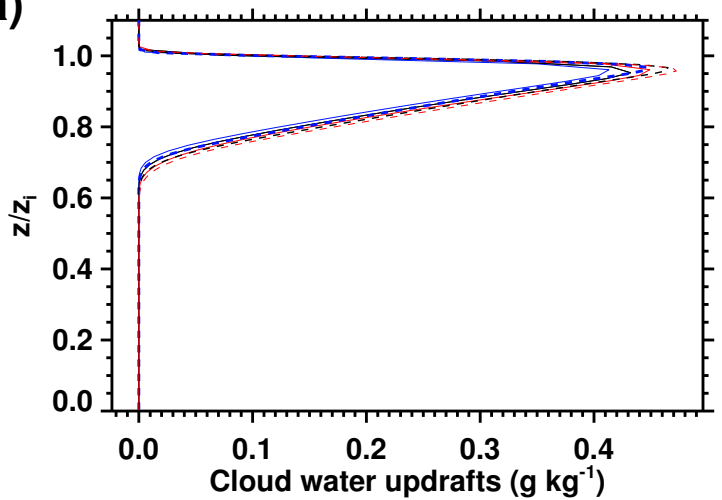

(c)

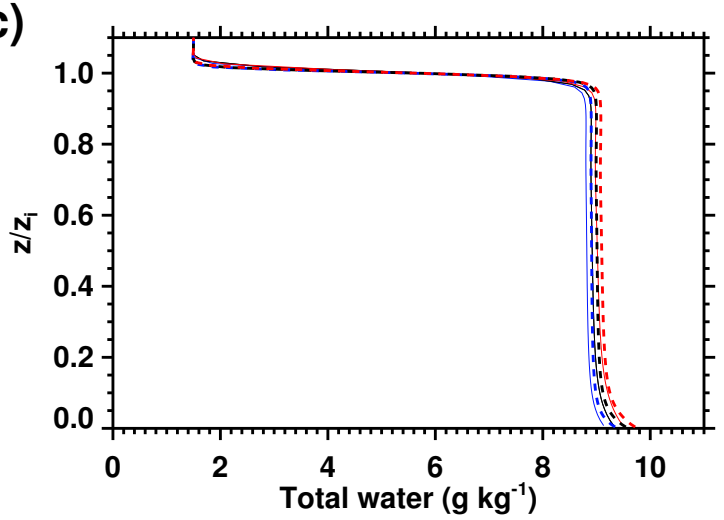

(b)

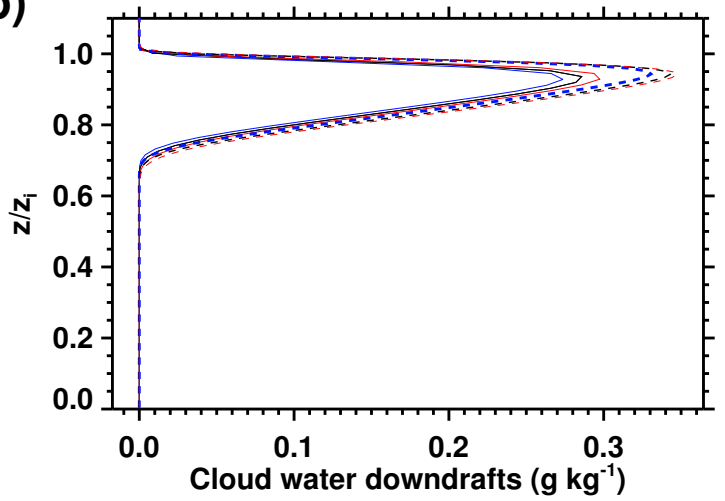

(d)

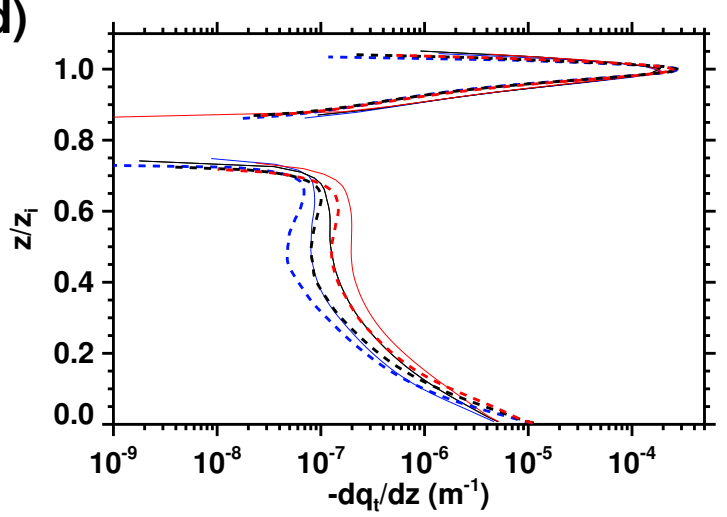

Figure C5. Effect of resolution. Profiles averaged over the period N (10:20-11:20 UT) from simulations $M^{-}$(blue), $M^{0}$ (black), $M^{+}$(red), solid curves, and from simulations $M_{\text {fine }}^{-}$(blue), $M_{\text {fine }}^{0}$ (black), $M_{\text {fine }}^{+}($red), dashed curves.

(a)

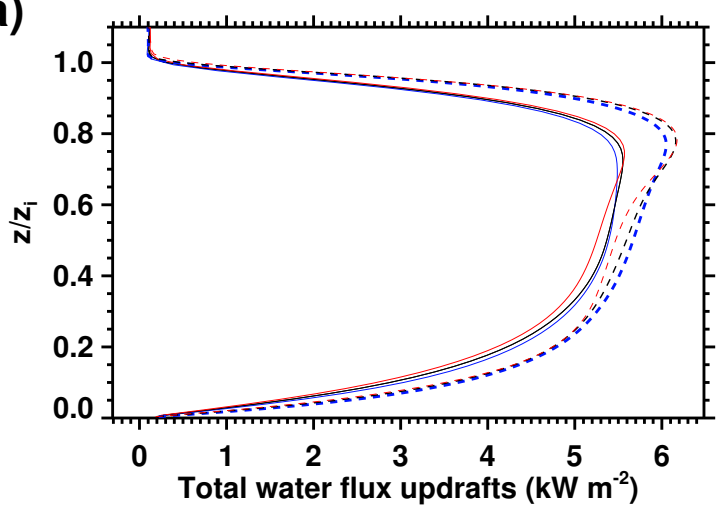

(b)

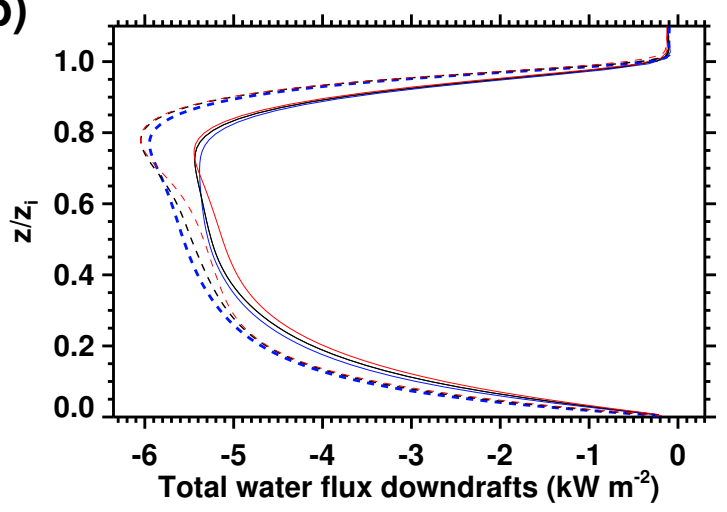

Figure C6. Effect of resolution. Profiles averaged over the period N (10:20-11:20 UT) from simulations $M^{-}$(blue), $M^{0}$ (black), $M^{+}$(red), solid curves, and from simulations $M_{\text {fine }}^{-}$(blue), $M_{\text {fine }}^{0}$ (black), $M_{\text {fine }}^{+}$(red), dashed curves. The total water flux is given per horizontal surface area of the domain. 
(a)

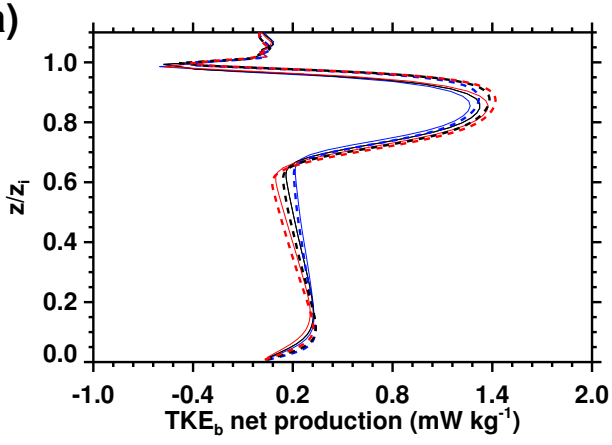

(c)

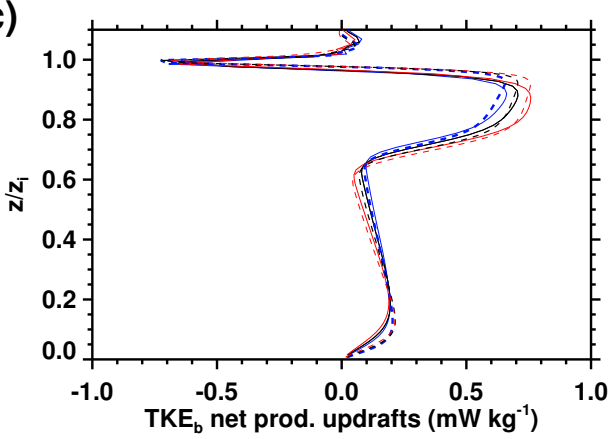

(b)

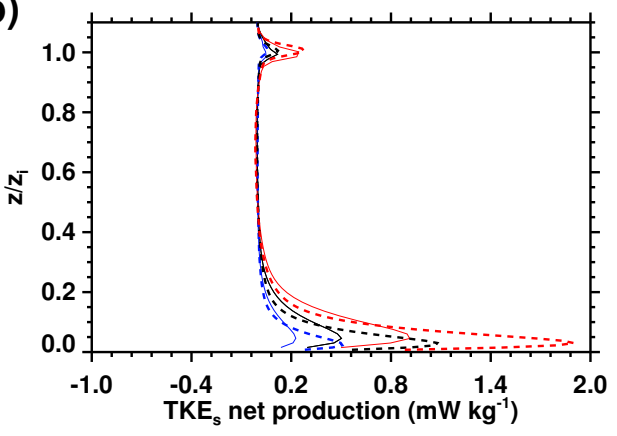

(d)

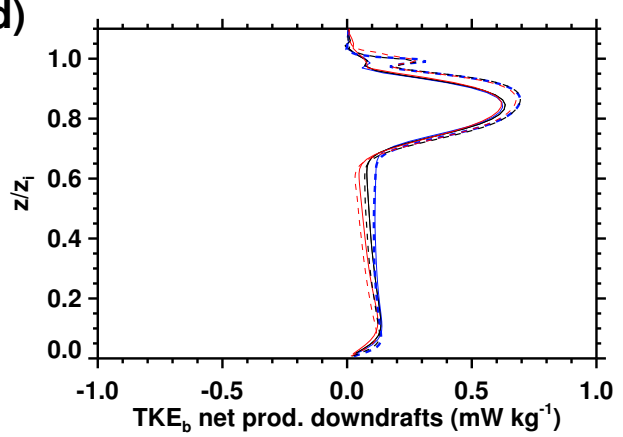

Figure C7. Effect of resolution. Profiles averaged over the period N (10:20-11:20 UT) from simulations $M^{-}$(blue), $M^{0}$ (black), $M^{+}$ (red), solid curves, and from simulations $M_{\text {fine }}^{-}$(blue), $M_{\text {fine }}^{0}$ (black), $M_{\text {fine }}^{+}\left(\right.$red), dashed curves. $\mathrm{TKE}_{\mathrm{b}}$ denotes buoyant production, $\mathrm{TKE}_{\mathrm{s}}$ shear production of turbulence kinetic energy. $\mathrm{TKE}_{\mathrm{b}}$ and $\mathrm{TKE}_{\mathrm{s}}$ in updrafts and downdrafts are air mass weighted sums over the updraft or downdraft locations at each level, respectively, normalized by the level air mass.

(a)

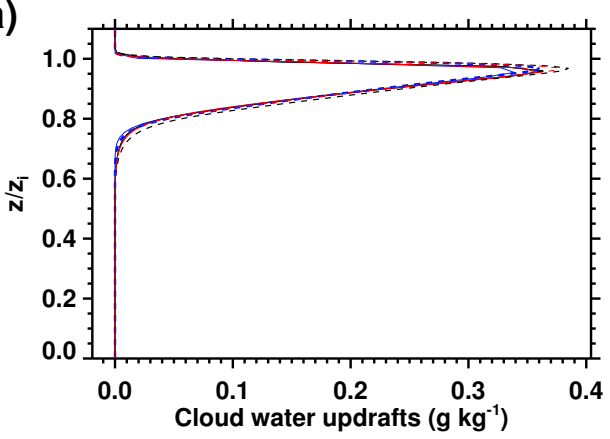

(c)

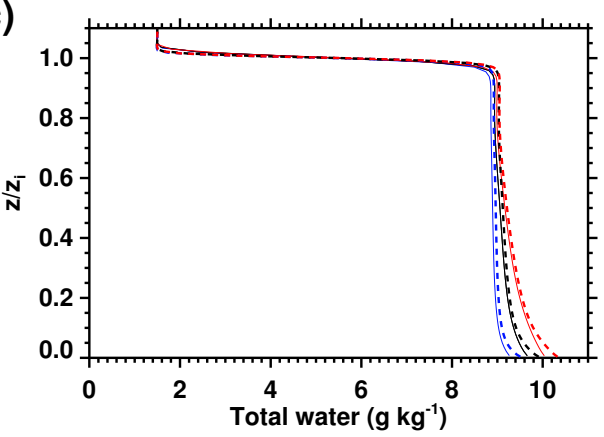

(b)

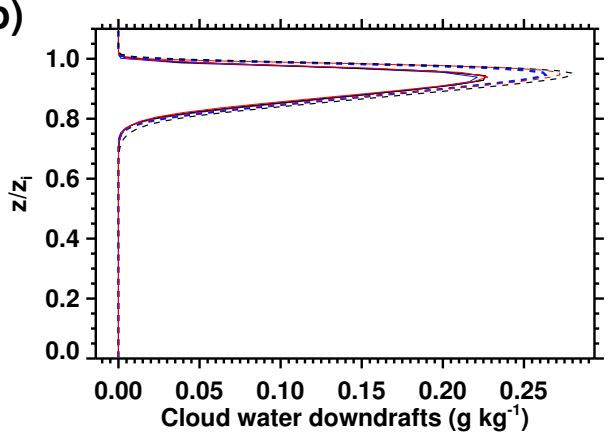

(d)

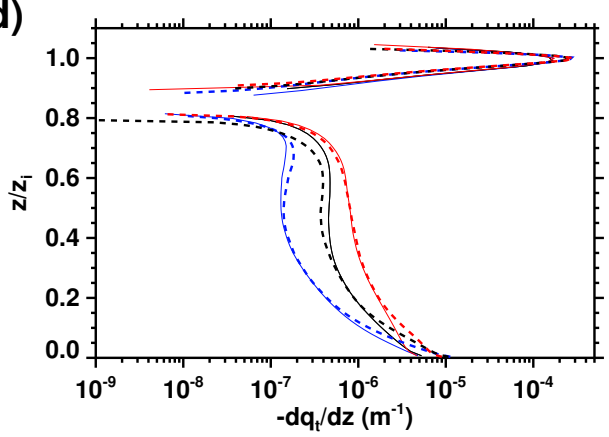

Figure C8. Effect of resolution. Profiles averaged over $1 \mathrm{~h}$ in the period C (22:30-23:30 UT) from simulations $M^{-}$(blue), $M^{0}$ (black), $M^{+}$ (red), solid curves, and from simulations $M_{\text {fine }}^{-}$(blue), $M_{\text {fine }}^{0}$ (black), $M_{\text {fine }}^{+}($(red), dashed curves. 
(a)

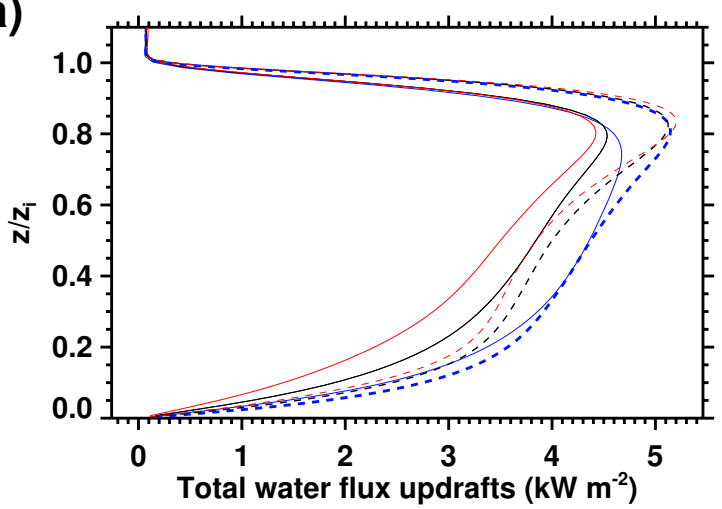

(b)

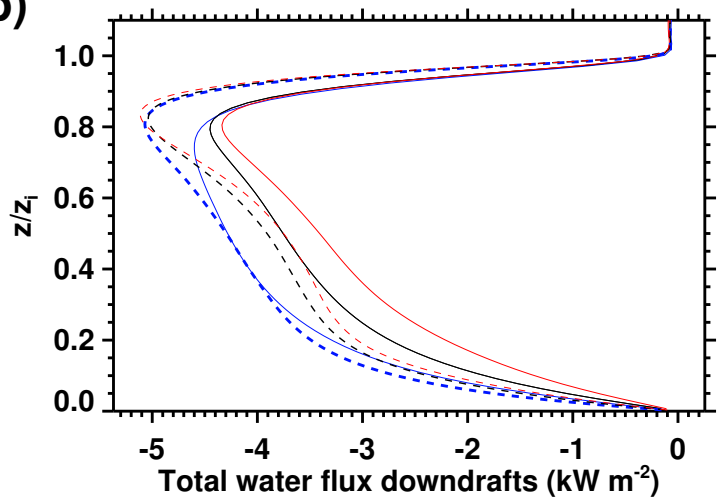

Figure C9. Effect of resolution. Profiles averaged over $1 \mathrm{~h}$ in the period C (22:30-23:30 UT) from simulations $M^{-}$(blue), $M^{0}$ (black), $M^{+}$ (red), solid curves, and from simulations $M_{\text {fine }}^{-}$(blue), $M_{\text {fine }}^{0}$ (black), $M_{\text {fine }}^{+}$(red), dashed curves. The total water flux is given per horizontal surface area of the domain.

(a)

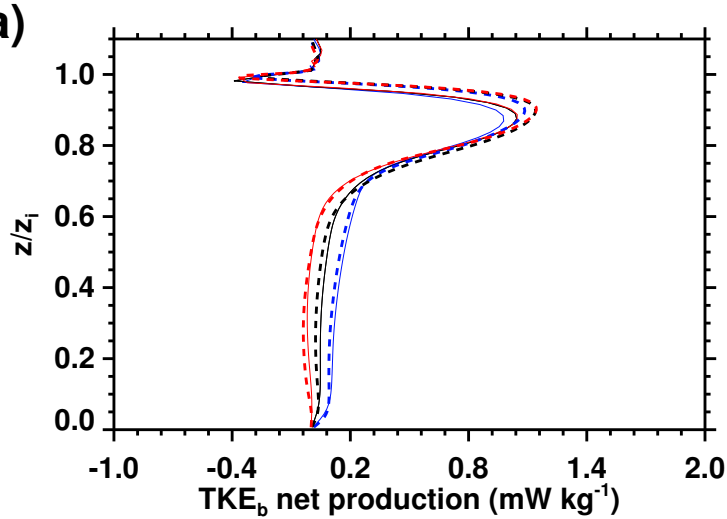

(c)

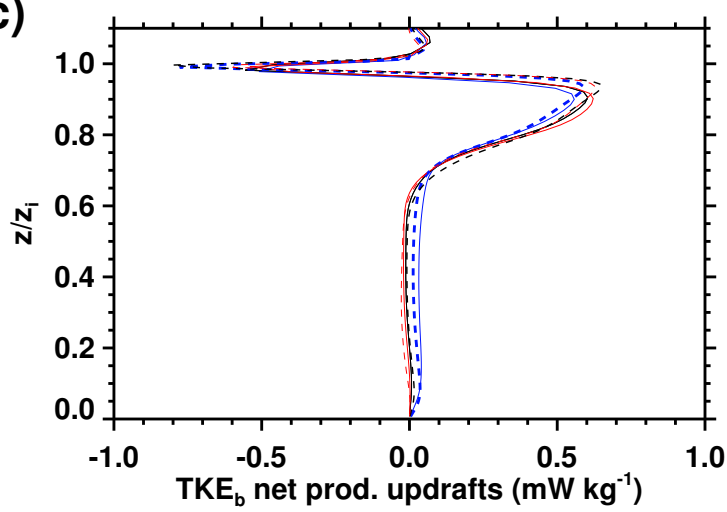

(b)

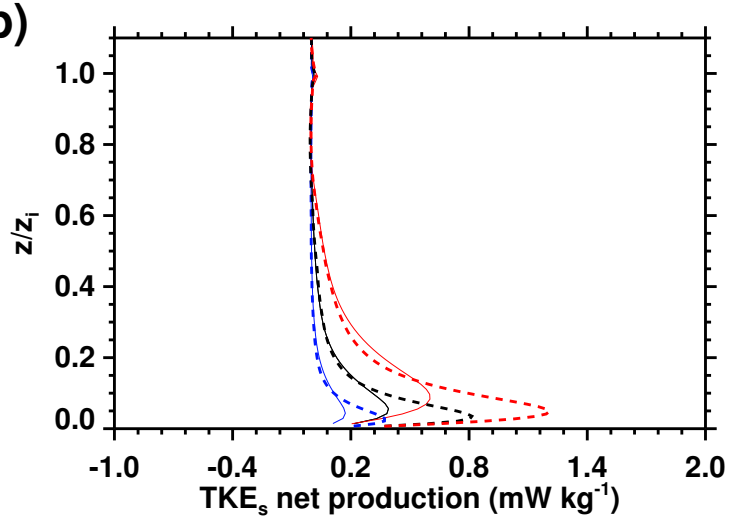

(d)

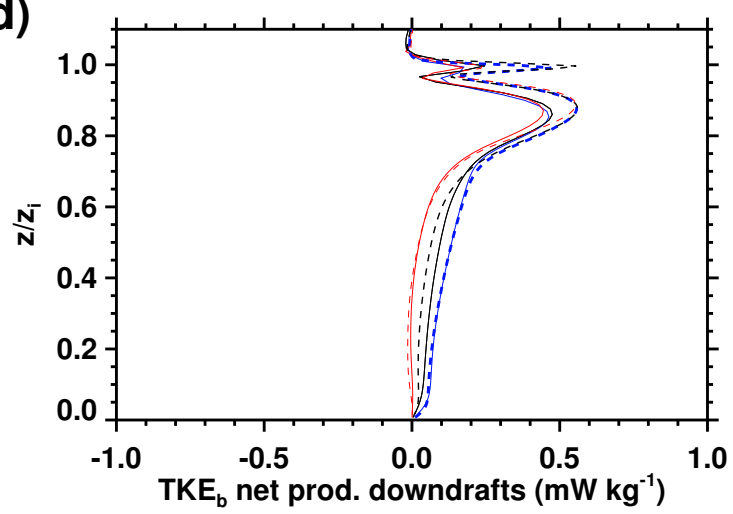

Figure C10. Effect of resolution. Profiles averaged over $1 \mathrm{~h}$ in the period C (22:30-23:30 UT) from simulations $M^{-}$(blue), $M^{0}$ (black), $M^{+}$ (red), solid curves, and from simulations $M_{\text {fine }}^{-}$(blue), $M_{\text {fine }}^{0}$ (black), $M_{\text {fine }}^{+}$(red), dashed curves. TKE $\mathrm{b}_{\mathrm{b}}$ denotes buoyant production, TKE shear production of turbulence kinetic energy. $\mathrm{TKE}_{\mathrm{b}}$ and $\mathrm{TKE}_{\mathrm{s}}$ in updrafts and downdrafts are air mass weighted sums over the updraft or downdraft locations at each level, respectively, normalized by the level air mass. 
Acknowledgements. This work is supported by the US Department of Energy (DOE) Atmospheric System Research Program grant DE-SC0006972, the US National Oceanic and Atmospheric Administration (NOAA) Climate Program Office through the Climate Process Team, Cloud Macrophysical Parameterization and its Application to Aerosol Indirect Effects, and by NOAA's Climate Goal. The authors acknowledge the NOAA Research and Development High Performance Computing Program for providing computing and storage resources that have contributed to the research results reported within this paper and thank two anonymous reviewers for their helpful comments.

Edited by: M. C. Facchini

\section{References}

Bertin, X., Prouteau, E., and Letetrel, C.: A significant increase in wave height in the North Atlantic Ocean over the 20th century, Global Planet. Change, 106, 77-83, doi:10.1016/j.gloplacha.2013.03.009, 2013.

Blossey, P. N., Bretherton, C. S., Zhang, M., Cheng, A., Endo, S., Heus, T., Liu, Y., Lock, A. P., Roode, S. R., and Xu, K.-M.: Marine low cloud sensitivity to an idealized climate change: The CGILS LES intercomparison, J. Adv. Mod. Earth Syst., 5, 234258, doi:10.1002/jame.20025, 2013.

Bony, S. and Dufresne, J.-L.: Marine boundary layer clouds at the heart of tropical cloud feedback uncertainties in climate models, Geophys. Res. Lett., 32, L20806, doi:10.1029/2005GL023851, 2005.

Bretherton, C. S.: A conceptual model of the stratus-trade cumulus transition in the subtropical oceans, in: Proc. 11th Int. Conf. on Clouds and Precipitation, vol. 1, Montreal, PQ, Canada, Int., comm. on Clouds and Precip. and Int. Assoc. Meteor. Atmos. Physics, 374-377, 1992.

Bretherton, C. S. and Wyant, M. C.: Moisture transport, lowertropospheric stability, and decoupling of cloud-topped boundary layers, J. Atmos. Sci., 54, 148-167, doi:10.1175/15200469(1997)054<0148:MTLTSA>2.0.CO;2, 1997.

Bretherton, C. S., Blossey, P. N., and Jones, C. R.: Mechanisms of marine low cloud sensitivity to idealized climate perturbations: A single-LES exploration extending the CGILS cases, J. Adv. Mod. Earth Syst., 5, 316-337, doi:10.1002/jame.20019, 2013.

Bretherton, C. S., Blossey, P. N., and Stan, C.: Cloud feedbacks on greenhouse warming in the superparameterized climate model SP-CCSM4, J. Adv. Mod. Earth Syst., 6, 1185-1204, doi:10.1002/2014MS000355, 2014.

Brient, F. and Bony, S.: Interpretation of the positive low-cloud feedback predicted by a climate model under global warming, Clim. Dynam., 40, 2415-2431, doi:10.1007/s00382-011-1279-7, 2013.

Caldwell, P. and Bretherton, C. S.: Response of a subtropical stratocumulus-capped mixed layer to climate and aerosol changes, J. Climate, 22, 20-38, doi:10.1175/2008JCLI1967.1, 2009.

Chen, Y.-C., Xue, L., Lebo, Z. J., Wang, H., Rasmussen, R. M., and Seinfeld, J. H.: A comprehensive numerical study of aerosolcloud-precipitation interactions in marine stratocumulus, Atmo.
Chem. Phys., 11, 9749-9769, doi:10.5194/acp-11-9749-2011, 2011.

Clement, A. C., Burgman, R., and Norris, J. R.: Observational and Model Evidence for Positive Low-Level Cloud Feedback, Science, 325, 460-464, doi:10.1126/science.1171255, 2009.

Colón-Robles, M., Rauber, R. M., and Jensen, J. B.: Influence of low-level wind speed on droplet spectra near cloud base in trade wind cumulus, Geophys. Res. Lett., 33, L20814, doi:10.1029/2006GL027487, 2006.

Dal Gesso, S., van der Dussen, J. J., Siebesma, A. P., de Roode, S. R., Boutle, I. A., Kamae, Y., Roehrig, R., and Vial, J.: A singlecolumn model intercomparison on the stratocumulus representation in present-day and future climate, J. Adv. Mod. Earth Syst., 7, 617-647, doi:10.1002/2014MS000377, 2015.

Dobrynin, M., Murawski, J., Baehr, J., and Ilyina, T.: Detection and attribution of climate change signal in ocean wind waves, J. Climate, 28, 1578-1591, doi:10.1175/JCLI-D-13-00664.1, 2015.

Grell, G. A., Peckham, S. E., Schmitz, R., McKeen, S. A., Frost, G., Skamarock, W. C., and Eder, B.: Fully coupled "online" chemistry within WRF model, Atmos. Environ., 39, 6957-6975, doi:10.1016/j.atmosenv.2005.04.027, 2005.

Hande, L. B., Siems, S. T., and Manton, M. J.: Observed trends in wind speed over the Southern Ocean, Geophys. Res. Lett., 39, L11802, doi:10.1029/2012GL051734, 2012.

Hartmann, D. L. and Doelling, D.: On the net radiative effectiveness of clouds, J. Geophys. Res., 96, 869-891, doi:10.1029/90JD02065, 1991.

Hartmann, D. L. and Short, D. A.: On the use of earth radiation budget statistics for studies of clouds and climate, J. Atmos. Sci., 37, 1233-1250, doi:10.1175/15200469(1980)037<1233:OTUOER>2.0.CO;2, 1980.

Hartmann, D. L., Ockert-Bell, M. E., and Michelsen, M. L.: The effect of cloud type on earth's energy balance: global analysis, J. Climate, 5, 1281-1304, doi:10.1175/15200442(1992)005<1281:TEOCTO>2.0.CO;2, 1992.

Hemer, M. A., Fan, Y., Mori, N., Semedo, A., and Wang, X. L.: Projected changes in wave climate from a multi-model ensemble, Nat. Clim. Change, 3, 471-476, doi:10.1038/nclimate1791, 2013.

Jeuken, A. B. M., Siegmund, P. C., Heijboer, L. C., Feichter, J., and Bengtsson, L.: On the potential of assimilating meteorological analyses in a global climate model for the purpose of model validation, J. Geophys. Res., 101, 16939-16950, doi:10.1029/96JD01218, 1996.

Jones, C. R., Bretherton, C. S., and Blossey, P. N.: Fast stratocumulus time scale in mixed layer model and large eddy simulation, J. Adv. Mod. Earth Syst., 6, 206-222, doi:10.1002/2013MS000289, 2014.

Katzwinkel, J., Siebert, H., and Shaw, R. A.: Observation of a Self-Limiting, Shear-Induced Turbulent Inversion Layer Above Marine Stratocumulus, Bound.-Lay. Meteorol., 145, 131-143, doi:10.1007/s10546-011-9683-4, 2012.

Kazil, J., Wang, H., Feingold, G., Clarke, A. D., Snider, J. R., and Bandy, A. R.: Modeling chemical and aerosol processes in the transition from closed to open cells during VOCALS-REx, Atmos. Chem. Phys., 11, 7491-7514, doi:10.5194/acp-11-74912011, 2011.

Kazil, J., Feingold, G., Wang, H., and Yamaguchi, T.: On the interaction between marine boundary layer cellular cloudi- 
ness and surface heat fluxes, Atmos. Chem. Phys., 14, 61-79, doi:10.5194/acp-14-61-2014, 2014.

Krueger, S. K., McLean, G. T., and Fu, Q.: Numerical Simulation of the Stratus-to-Cumulus Transition in the Subtropical Marine Boundary Layer. Part I: Boundary-Layer Structure, J. Atmos. Sci., 52, 2839-2850, doi:10.1175/15200469(1995)052<2839:NSOTST>2.0.CO;2, 1995a.

Krueger, S. K., McLean, G. T., and Fu, Q.: Numerical Simulation of the Stratus-to-Cumulus Transition in the Subtropical Marine Boundary Layer. Part II: Boundary-Layer Circulation, J. Atmos. Sci., 52, 2851-2868, doi:10.1175/15200469(1995)052<2851:NSOTST>2.0.CO;2, 1995 b.

McInnes, K. L., Erwin, T. A., and Bathols, J. M.: Global climate model projected changes in $10 \mathrm{~m}$ wind speed and direction due to anthropogenic climate change, Atmos. Sci. Lett., 12, 325-333, doi:10.1002/asl.341, 2011.

Meehl, G. A., Covey, C., Delworth, T., Latif, M., McAvaney, B., Mitchell, J. F. B., Stouffer, R. J., and Taylor, K. E.: The WCRP CMIP3 multimodel dataset: a new era in climate change research, B. Am. Meteorol. Soc., 88, 1383-1394, doi:10.1175/BAMS-88-9-1383, 2007.

Mellado, J. P., Stevens, B., and Schmidt, H.: Wind Shear and Buoyancy Reversal at the Top of Stratocumulus, J. Atmos. Sci., 71, 1040-1057, doi:10.1175/JAS-D-13-0189.1, 2014.

Nuijens, L. and Stevens, B.: The influence of wind speed on shallow marine cumulus convection, J. Atmos. Sci., 69, 168-184, doi:10.1175/JAS-D-11-02.1, 2012.

Petters, J. L.: The impact of radiative heating and cooling on marine stratocumulus dynamics, $\mathrm{PhD}$ thesis, The Pennsylvania State University, University Park, Pennsylvania, USA, 161 pp., 2009.

Schneider, S. H.: Cloudiness as a global climatic feedback mechanism: the effects on the radiation balance and surface temperature of variations in cloudiness, J. Atmos. Sci., 29, 1413-1422, doi:10.1175/1520-0469(1972)029<1413:CAAGCF>2.0.CO;2, 1972.

Schubert, W. H., Wakefield, J. S., Steiner, E. J., and Cox, S. K.: Marine stratocumulus convection. part II: horizontally inhomogeneous solutions, J. Atmos. Sci., 36, 1308-1324, doi:10.1175/1520-0469(1979)036<1308:MSCPIH>2.0.CO;2, 1979.

Servain, J., Caniaux, G., Kouadio, Y. K., McPhaden, M. J., and Araujo, M.: Recent climatic trends in the tropical Atlantic, Clim. Dynam., 43, 3071-3089, doi:10.1007/s00382-014-2168-7, 2014.

Skamarock, W. C., Klemp, J. B., Dudhia, J., Gill, D. O., Barker, D. M., Duda, M. G., Huang, X.-Y., Wang, W., and Powers, J. G.: A Description of the Advanced Research WRF Version 3, Tech. Rep. NCAR/TN-475+STR, National Center for Atmospheric Research, Boulder, CO, USA, 2008.

Soden, B. J. and Vecchi, G. A.: The vertical distribution of cloud feedback in coupled ocean-atmosphere models, Geophys. Res. Lett., 38, L12704, doi:10.1029/2011GL047632, 2011.

Stephens, G. L.: Cloud feedbacks in the climate system: a critical review, J. Climate, 18, 237-273, doi:10.1175/JCLI-3243.1, 2005.

Stevens, B., Moeng, C.-H., Ackerman, A. S., Bretherton, C. S., Chlond, A., de Roode, S., Edwards, J., Golaz, J.-C., Jiang, H., Khairoutdinov, M., Kirkpatrick, M. P., Lewellen, D. C., Lock, A., Müller, F., Stevens, D. E., Whelan, E., and Zhu, P.: Evaluation of large-eddy simulations via observations of noctur- nal marine stratocumulus, Mon. Weather Rev., 133, 1443-1462, doi:10.1175/MWR2930.1, 2005.

Turton, J. D. and Nicholls, S.: A study of the diurnal variation of stratocumulus using a multiple mixed layer model, Q. J. Roy. Meteorol. Soc., 113, 969-1009, doi:10.1002/qj.49711347712, 1987.

van der Dussen, J. J., de Roode, S. R., Gesso, S. D., and Siebesma, A. P.: An LES model study of the influence of the free tropospheric thermodynamic conditions on the stratocumulus response to a climate perturbation, J. Adv. Mod. Earth Syst., 7, 670-691, doi:10.1002/2014MS000380, 2015.

Wang, S., Golaz, J.-C., and Wang, Q.: Effect of intense wind shear across the inversion on stratocumulus clouds, Geophys. Res. Lett., 35, L15814, doi:10.1029/2008GL033865, 2008.

Wang, S., Zheng, X., and Jiang, Q.: Strongly sheared stratocumulus convection: an observationally based large-eddy simulation study, Atmos. Chem. Phys., 12, 5223-5235, doi:10.5194/acp-125223-2012, 2012.

Webb, M. J., Senior, C. A., Sexton, D. M. H., Ingram, W. J., Williams, K. D., Ringer, M. A., McAvaney, B. J., Colman, R., Soden, B. J., Gudgel, R., Knutson, T., Emori, S., Ogura, T., Tsushima, Y., Andronova, N., Li, B., Musat, I., Bony, S., and Taylor, K. E.: On the contribution of local feedback mechanisms to the range of climate sensitivity in two GCM ensembles, Clim. Dynam., 27, 17-38, doi:10.1007/s00382-006-0111-2, 2006.

Williams, K. D. and Tselioudis, G.: GCM intercomparison of global cloud regimes: present-day evaluation and climate change response, Clim. Dynam., 29, 231-250, doi:10.1007/s00382-0070232-2, 2007.

Wood, R.: Stratocumulus Clouds, Mon. Weather Rev., 140, 2373 2423, doi:10.1175/MWR-D-11-00121.1, 2012.

Wyant, M. C., Bretherton, C. S., Rand, H. A., and Stevens, D. E.: Numerical simulations and a conceptual model of the stratocumulus to trade cumulus transition, J. Atmos. Sci., 54, 168-192, doi:10.1175/1520-0469(1997)054<0168:NSAACM>2.0.CO;2, 1997.

Wyant, M. C., Bretherton, C. S., Bacmeister, J. T., Kiehl, J. T., Held, I. M., Zhao, M., Klein, S. A., and Soden, B. J.: A comparison of low-latitude cloud properties and their response to climate change in three AGCMs sorted into regimes using mid-tropospheric vertical velocity, Clim. Dynam., 27, 261-279, doi:10.1007/s00382-006-0138-4, 2006.

Xu, K.-M., Cheng, A., and Zhang, M.: Cloud-resolving simulation of low-cloud feedback to an increase in sea surface temperature, J. Atmos. Sci., 67, 730-748, doi:10.1175/2009JAS3239.1, 2010.

Young, I. R., Zieger, S., and Babanin, A. V.: Global trends in wind speed and wave height, Science, 332, 451-455, doi:10.1126/science.1197219, 2011.

Zhou, C., Zelinka, M. D., Dessler, A. E., and Yang, P.: An analysis of the short-term cloud feedback using MODIS data, J. Climate, 26, 4803-4815, doi:10.1175/JCLI-D-12-00547.1, 2013. 